\title{
توجه الجامعات لتحقيق الميزة التنافسية بالاعتماد على مبادئ تدويل التعلير العالي بعا يتوافق مع متطلبات أهداف مشروع نيوم
}

\author{
نجوى الفواز
}

\section{Doi: //10.47015/16.4.1}

The Universities Tendency to Achieve Competitive Advantage Based on the Principles of Internationalization of Higher Education in Line with the Requirements of the Objectives of the Neom Project

\section{Najwa Al-Fawaz, Tabuk University,Saudi Arabia.}

Abstract: The present study aims to identify the tendency of the University of Tabuk to achieve competitive advantage, based on the principles of internationalization of higher education, in accordance with the requirements of Neom project. To achieve the aims of the study, the researcher used the descriptive analytical method. The sample of the study was randomly selected and consisted of (53) academic leaders at the University of Tabuk (deans of colleges). The researcher used a questionnaire as the main tool applied to collect data and answer the research questions. The results of the study showed that the University of Tabuk has shown a very high tendency to achieve competitive advantage, based on the principles of internationalization of higher education in line with the requirements of the neom project. It was also shown that the Neom project faces great obstacles to achieve competitive advantage. The results of the study also showed that the University of Tabuk achieved a very high degree in the dimension of the requirements to achieve competitive advantage, based on the principles of internationalization of higher education. The results of the study revealed no statistically significant differences in the degree of the tendency of the University of Tabuk to achieve competitive advantage, in accordance with the principles of internationalization of higher education in line with the requirements of the Neom project due to the variables: "functional tasks, gender, academic rank and years of experience".

(Keywords: Competitive Advantage of Universities, Internationalzation of Higher Education, Neom Project)

وتبـرز أهميـة تـدويل التعليم العـالي باعتبـاره آليـة لتحقيـق الميـزة

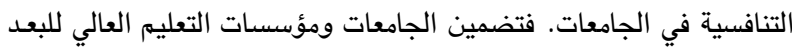

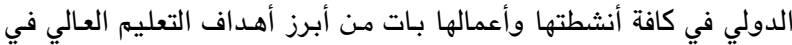

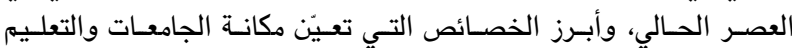

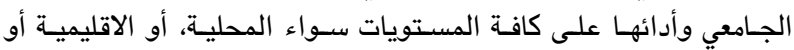

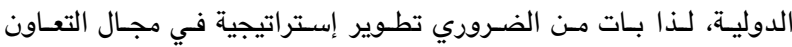

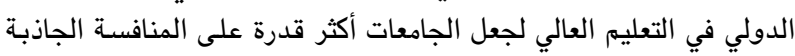
لكل من الأسواق المحلية والعالمية (Gunsyma,2014).

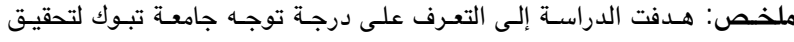

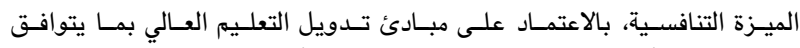

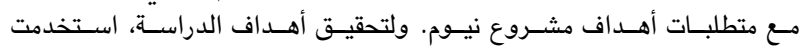

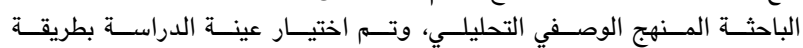

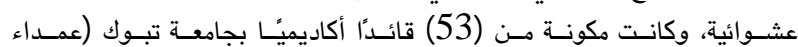

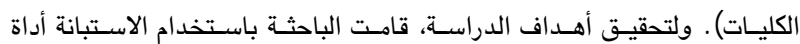

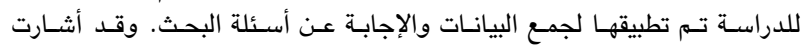

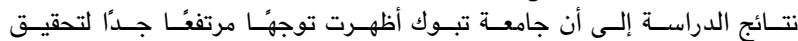

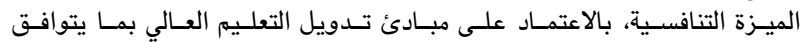

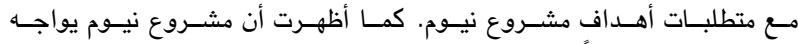

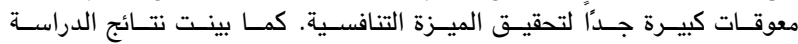

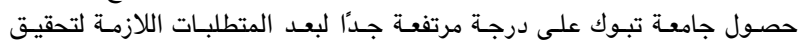

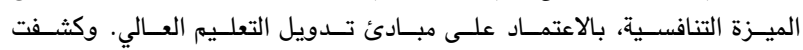

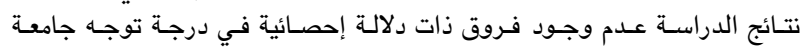

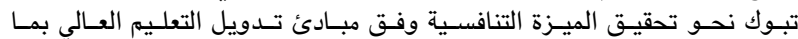

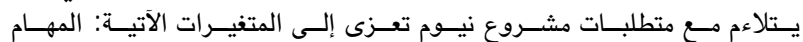

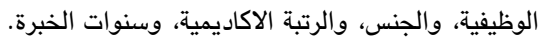

(الكلمات المفتاحية: الميزة التنافسية للجامعات، تدويل التعليم العالي، مشروع نيوم)

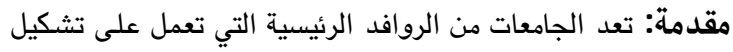

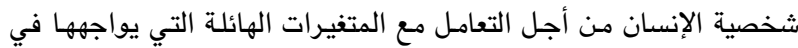

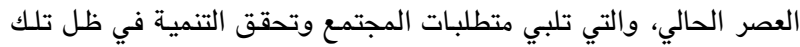

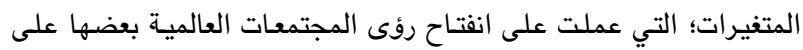

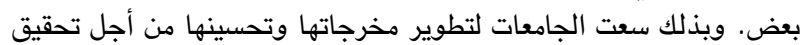

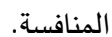

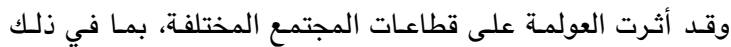

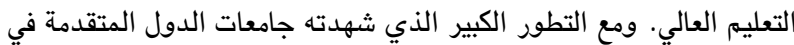

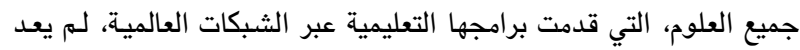

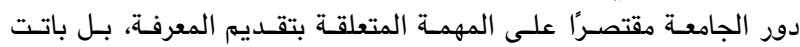

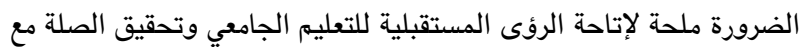

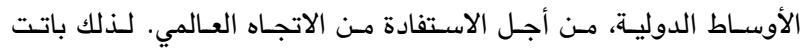

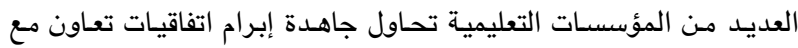

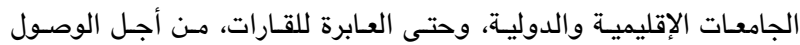
بالتعليم الجامعي نحو العالمية (Jibeen \& Khan, 2015).

( ) جامعة تبوك، السعودية. C حقوق الطبع محفوظة لجامعة اليرموك، إربد، الأردن. 
لكن التغيرات العالمية المتلاحقة، وظهور العولمة، وبروز

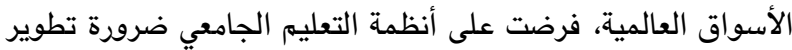

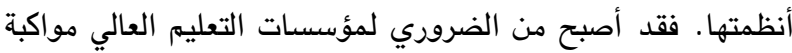

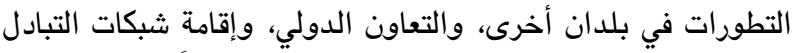
والتواصل؛ إذ باتت الدول النامية مهددة مستقبلا بالتهميش في الاقتصاديات العالمية التنافسية، ما لهم يتم تطويرها نحو الاستثمار

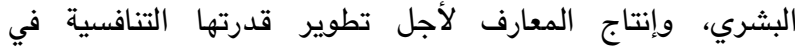
الاقتصاد العالمي، ووصولها إلى الميزة التنافسية. وهذا أدى إلى إلى الى

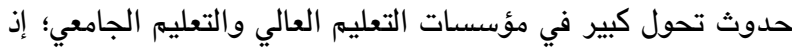

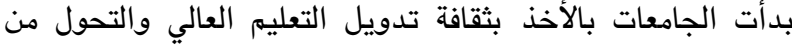

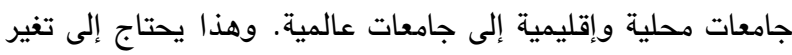
جوهري في فلسفة التعليم العالي وتغيير توجهاته واستراتيجياته؛

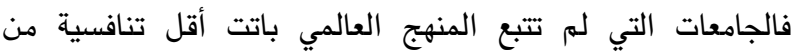
الجامعات التي أخذت الصبغة العالمية (

. (Tiwari, 2014

Mainardes \& Ferreira, ) وقد أشار ميناردس وفريرا

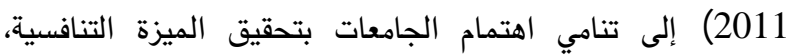
والتوجه نحو التضامن بين الجامعات العالمية، والاشتراك في المهام

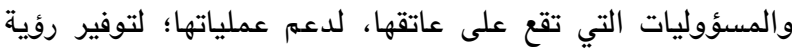

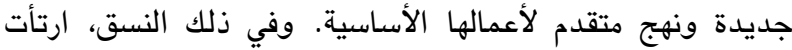

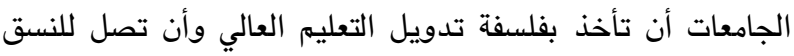

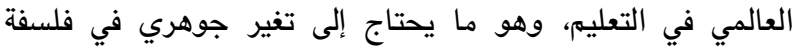

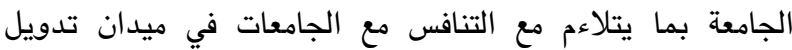

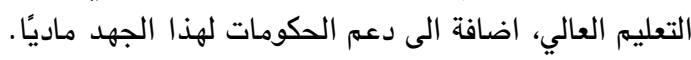

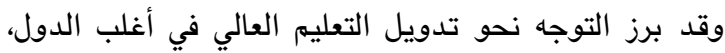

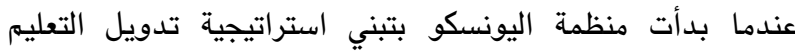

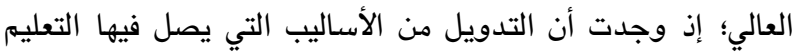

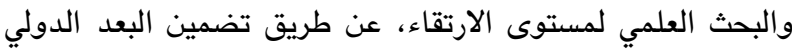

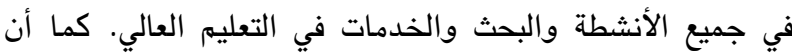

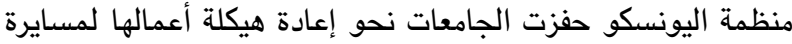

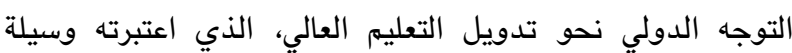

للتنافس على الصعيدين المحلي والعالمي (Gao, 2015). ويشير تشن (Chen, 2011) إلى أن تدويل التعليم العالي

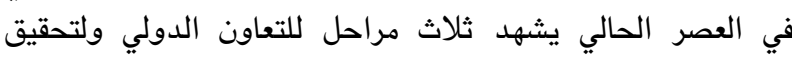
التدويل في ميدان التعليم العالي، جاءت على النحو الآتي: 1. المرحلة الأولى: تشتمل على التدويل في سفر الطلاب وانتقالهم من موطنهم الأصلي إلى الدول المتقدمة لإكمال دراستهم.

2. المرحلة الثانية: تمثل التعاون والترابط بين جامعات العالم لأجل التاني التبادل العلمي، وعقد الاتفاقيات العالمية بينَ الجامعات، وإعداد التراد برامج للإشراف المشترك بين الجامعات.
فتـدويل التعليم العـالي يعمـل على إكسـاب الجامعـات البصـمة

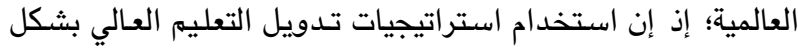

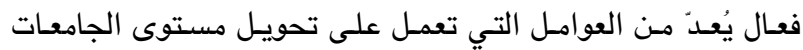

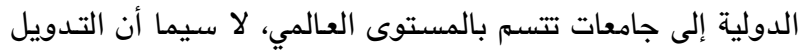

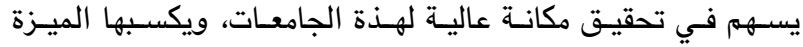

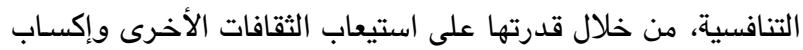

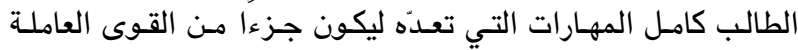

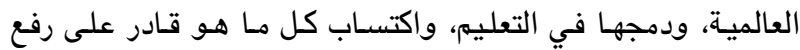

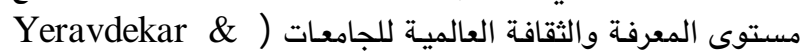
. (Tiwari, 2014

وقد جاء مشروع نيوم الذي أطلقه ولي العهد الأمير محمد

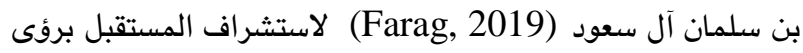
وتطلعات مستقبلية؛ إذ سوف يصبح أول منطقة ممتدة بين ثلاث

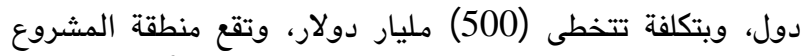

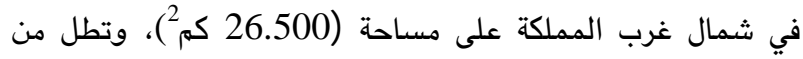

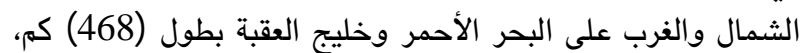

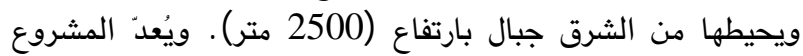

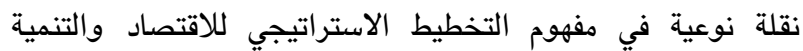
الشاملة المستدامة، لوضع المملكة العربية السعودية في طليعة

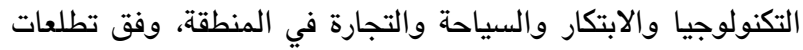

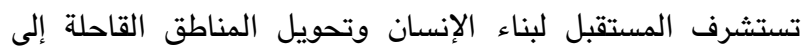
مدن حضارية، كتحويل منطقة تبوك إلى منطقة اقتصادية، وجعلها

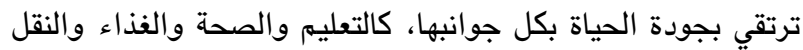

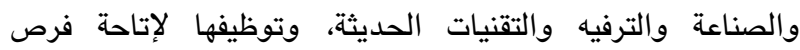

اقتصادية كبيرة (Minawi, 2019) .

وانتشر مفهوم الميزة التنافسية في الآونة الأخيرة؛ فقد سعت

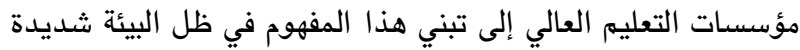

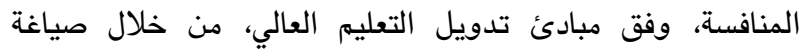

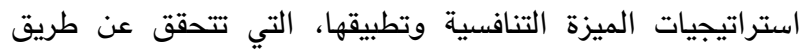

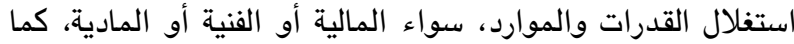
الكفاءات والمعارف والإمكانات التي تتميز بها الجامعة، والتي تتمكن

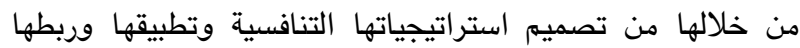
بتحقيق الميزة التنافسية، ببعديها : القيمة المدركة للمستفيد، وقيت وقدرة المؤسسة على تحقيق الميزة التنافسية (Alsaleh, 2012).

وقد سعت مؤسسات التعليم العالي إلى كسب ميزة تنافسية على غيرها من المؤسسات المنافسة؛ إذ تحقق التميز والتنافسية التولية من خلال استثمار الطاقات الفكرية. وتعرف المولف الميزة التنافسية للجامعات بأنها: " قدرة الجامعات على تحقيق الجودة التعليمية والحفاظ عليها، وزيادة كفاءتها الداخلية وزيادة الطلب عليها

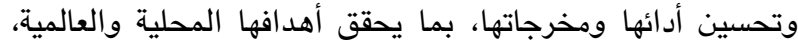

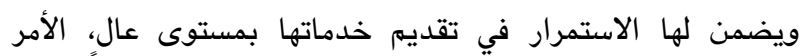
الذي يساعد في حصولها على مراكز متقدمة في الترتيب العالمي للجامعات والمؤسسات الأكاديمية والبحثية" (Aliabad, 2017). 
تضمن نجاح التدويل في تجويد التعليم العالي. وقد جاءت على الى

النحو الآتي (CBIE, 2014):

1. أن يضفي التدويل الدولي الصبغة الدولية على التعليم العالي،

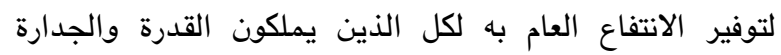
والتهيئة الملائمة من الأفراد على المستوى العالمي.

2. أن يوفر الطابع العالمي للتعليم العالي العديد من الأنماط المختلفة من التعليم استجابة للمتطلبات التعليمية لجميع الطلبة. 3. أن يهتم التعاون الدولي للتعليم في مجال التعليم العالي بالدور

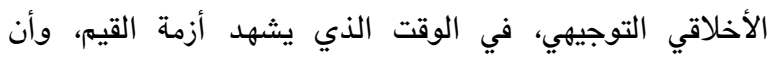
يضطلع بتطويره عبر تشكيل روابط تضامن عالمي وتفعيل أنشطة التئ

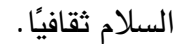

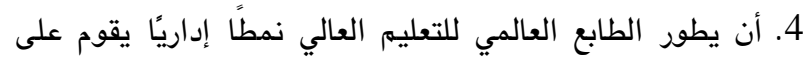

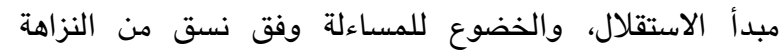

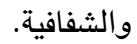

5. أن يقوم الطابع العالمي للتعليم العالي على مبدأ الجودة، وأن تتم صياغة معايير للجودة تتخطى المعايير المتعلقة بسياقات محددة. 6. أن يستند التعاون الدولي في مجال التعليم العالي إلى الترابط

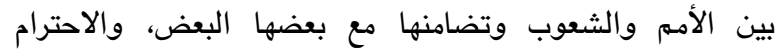
المتبادل، والعمل على تعزيز القيه والمبادئ الإنسانية، وتعزيز والثين

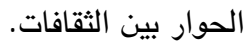

7. أن تنهض مؤسسات التعليم العالي بالمسؤولية الاجتماعية، التي

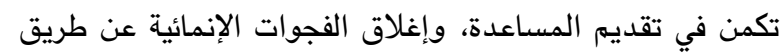

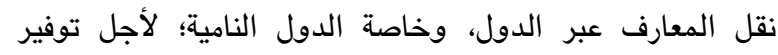

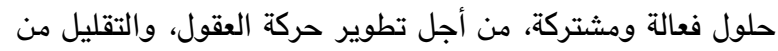

الآثار السلبية لهجرتها للدول الغربية.

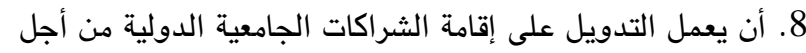

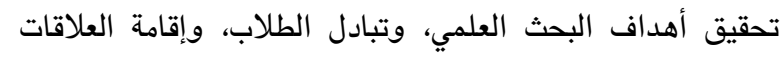

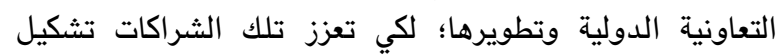

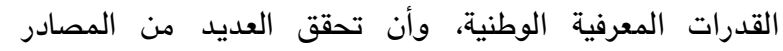

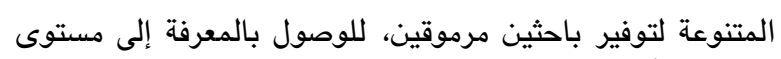

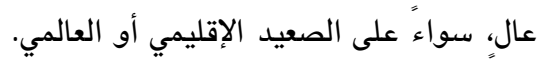

9. أن يضمن التدويل إتاحة فرص متكافئة للاستفادة من التعليم

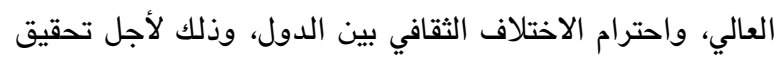
استفادة جميع الدول من تدويل التعليم العالي.

10. أن ينبثق التعاون الدولي بين الجامعات من الأنظمة الوطنية،

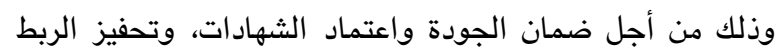

$$
\text { بينهما على الصعيد العالمي. }
$$

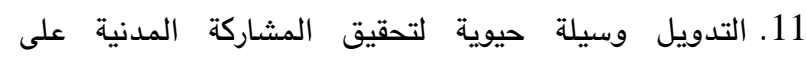

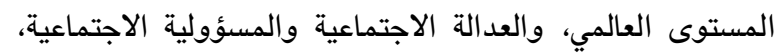
وبالتالي تحقيق المصلحة العامة. والعدالـ
3. المرحلة الثالثة: برزت في الآونة الأخيرة، وتكمن في فتح العديد

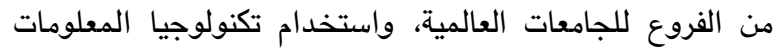
في التعليم (كالتعليم عن بعد)، والعمل على تشكيل الجامعات الفيات الافتراضية. - - - nي

وتبعًا لهذه المراحل التي جاء فيها التدويل في الوقت الحالي،

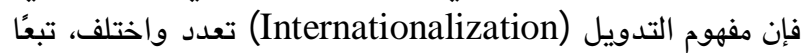

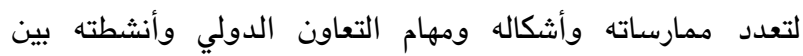

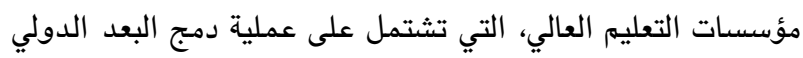

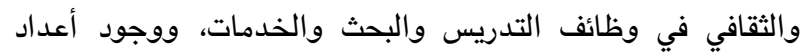

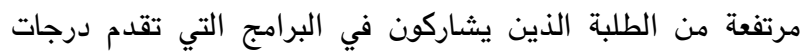

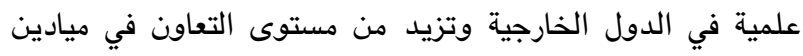

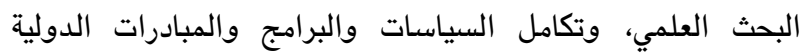

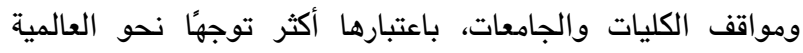

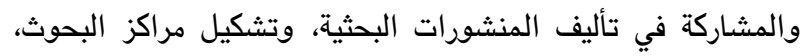

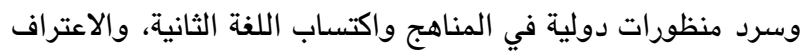

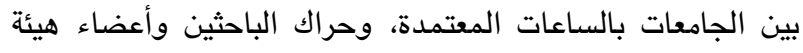

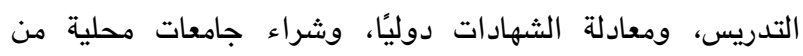

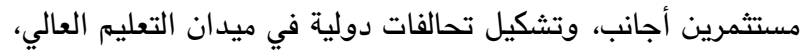
وتطوير مستويات علمية مشتركة عن بعد (Hawawini, 2016). ووفقًا لهذا التعدد، اختلفت وجهات النظر حول تعريف تدويل

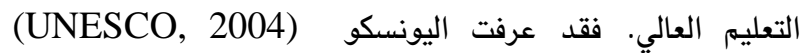

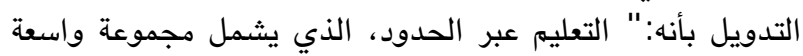

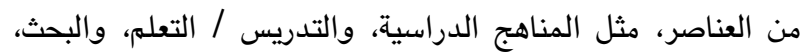

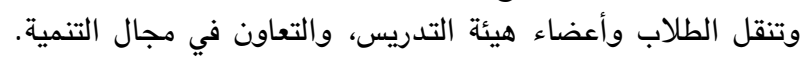

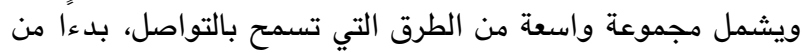

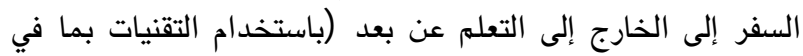
ذلك التعلم الإلكتروني)" . وعرفه العمري (Alamri, 2012) بأنه: عملية بناء فلسفة مؤسسية ذات استراتيجية وبنية تنظيمية دولية،

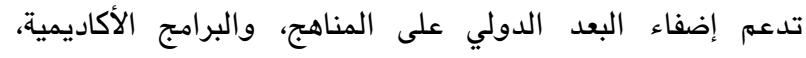

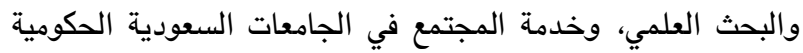

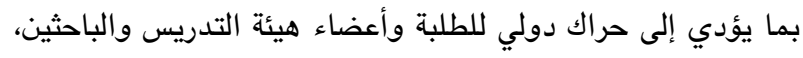

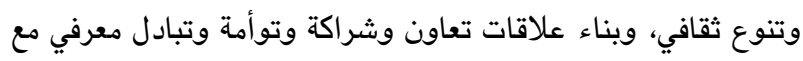
الجامعات العالمية. ويعرف هوانج

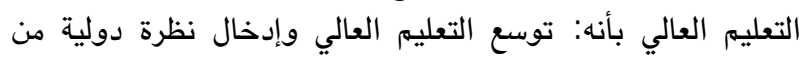

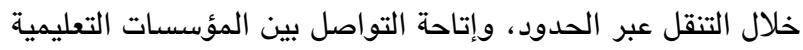

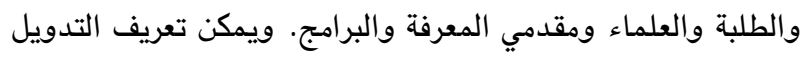

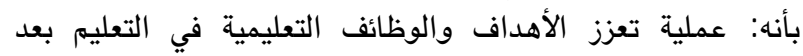

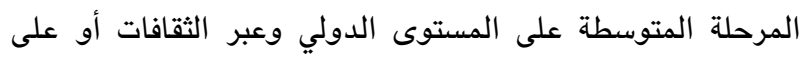

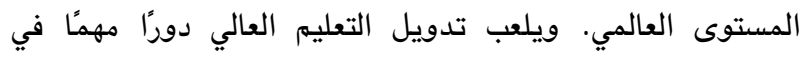

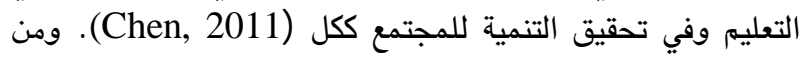

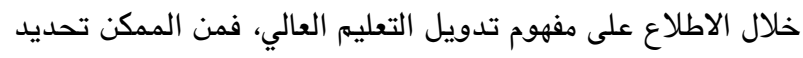
عدد من المبادئ التي ينطلق منها تدويل التعليم العالي، والتي التيلي التئي 
كما يرنو مشروم نيوم إلى دعم القطاعات الاقتصادية

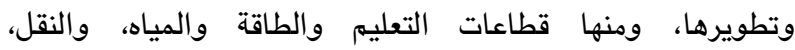

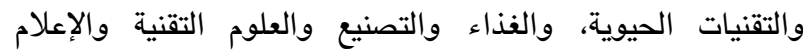

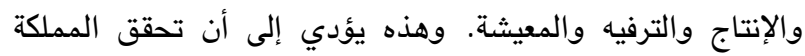

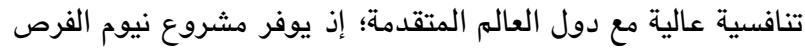

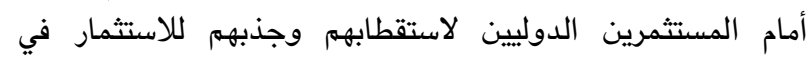
السعودية، لأجل الوصول إلى السوق السعودية، ومن ثم إلى الأسواق العالمية، لكون مشروع نيوم يربط بين ثلاث لون دول

. (Ministry of Foreign Affairs in Denmark, 2018)

ويقدم مشروع نيوم استثمارًا للكثير من المشاريع، وأبرزها

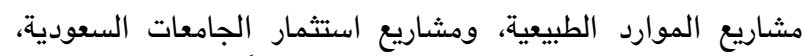

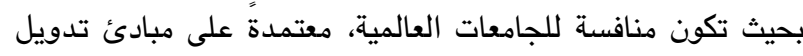

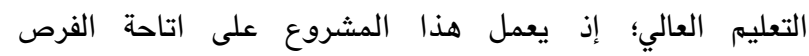
الاقتصادية، وتوفير سبل العيش المريح لمن يعيش في هذه إنه

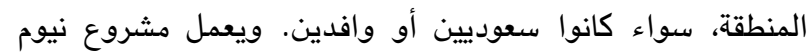

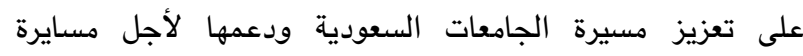

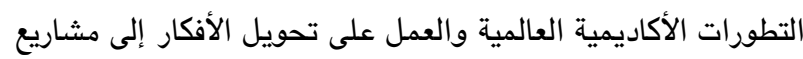

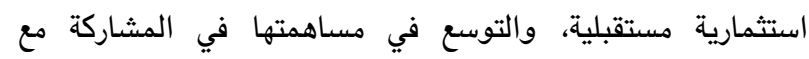

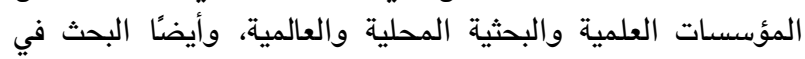
أساليب تطوير البحث العلمي في الجامعات، وتثبيت مفهوم التحول

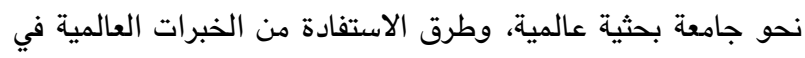

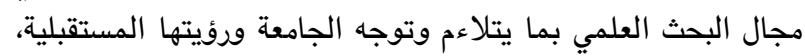

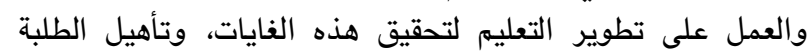

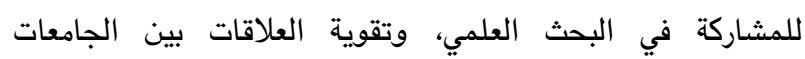

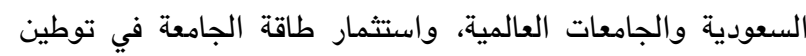

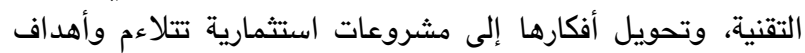
المملكة 2030 ورؤيتها (Saudi Vision, 2030).

ويتوقف نجاح هذا المشروع على إعداد كوادر سعودية مؤهلة تمتلك مهارات عالية ومتخصصة في جميع المجالات التي سيضمها المشروع، والتي تعمل على توطين فعاليات مشروع نيوم وضمان

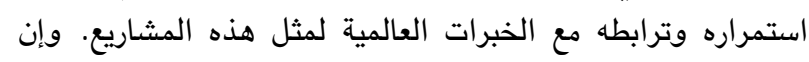

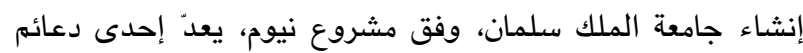

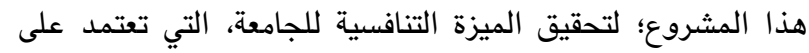

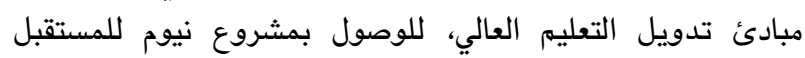

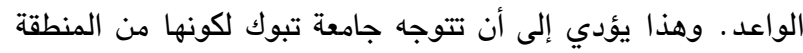
التي يتضمنها مشروع نيوم إلى تحقيق الميزة التنافسية في خططها

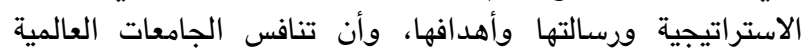

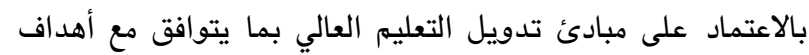
مشروع نيوم. - مثنمال

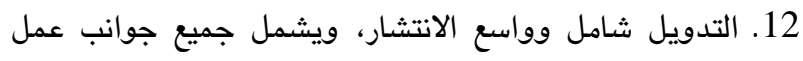

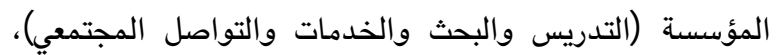

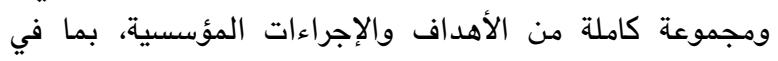

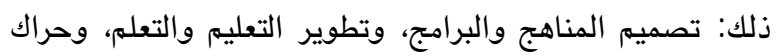

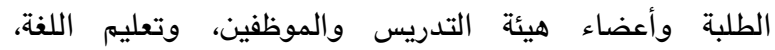

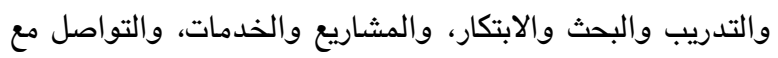
المجتمع والتنمية الاقتصادية المحلية.

13. التدويل مهم للاستدامة المالية للعديد من مؤسسات التعليم العالي، ولا ينبني القيام به دون تخصيص موارد كافية.

14. التدويل الذي يشمل بناء القدرات عبر الحدود والثقافات يجب

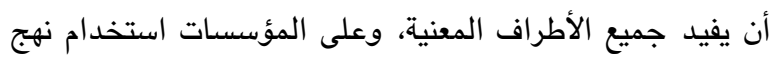
جماعي تشاركي مفيد لجميع الأطراف لإقامة شراكات عالمية.

15. في التدويل تشارك مجموعة واسعة من أفراد المجتمع (بما في

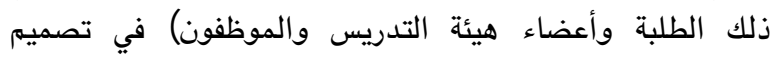
وتطوير الأنشطة. ويهدف إلى الوصول العادل للأنشطة. وإشراك الثاء جميع أعضاء مجتمع التعليم.

من خلال ما سبق، فإن الجامعات تسعى إلى تحقيق الميزة

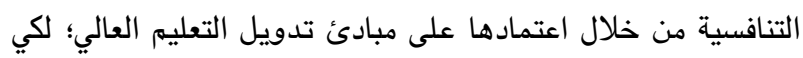

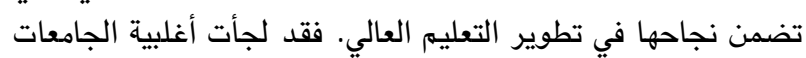

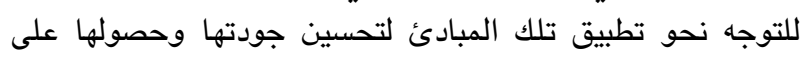

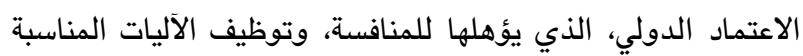

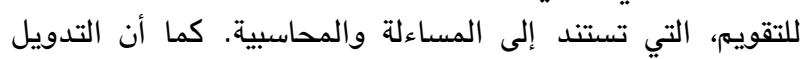
يحتاج إلى تقييم البرامج الدراسية وتطوير المقررات، بما يتلاءم

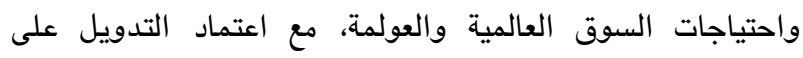
التعاون بين حميع الأطراف؛ لتحقيق الاعتدال في الحراك الطلابي

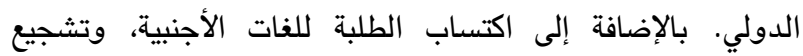

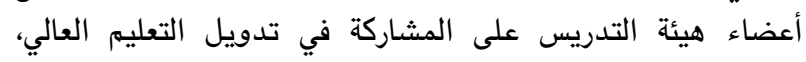
والاستفادة من التكنولوجيا والتعليم عن بعد، وضمان التئية حرية الطلبة فئية

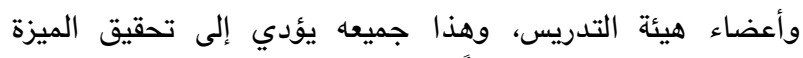

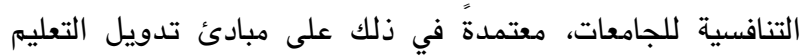

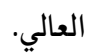

وتكمن متطلبات أهداف مشروع "نيوم" في التنويع في

اقتصاد السعودية المستقبلي، وجعلها منطقة اقتصادية مستقلة لها

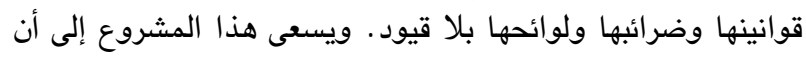

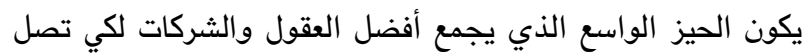
إلى أعلى مستوى في الإبداع من خلال الاهتمام بالتكنولوجيا

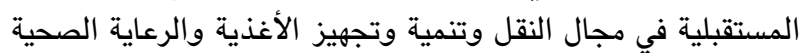

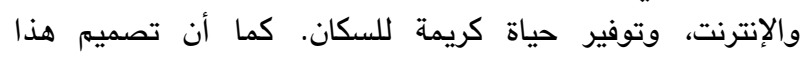

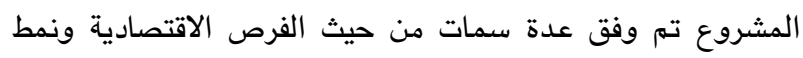

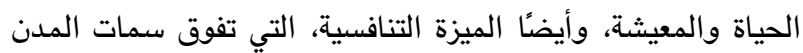
العالمية الكبرى (Farag, 2019) . 
كما أجرى نجوجي (Ngugi, 2014) دراسة حول خلق ميزة

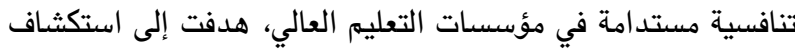

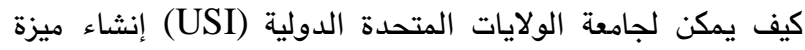

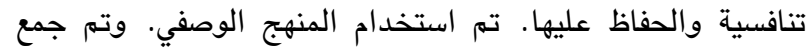

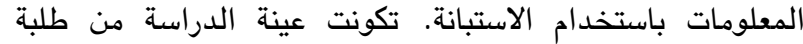

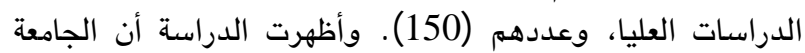

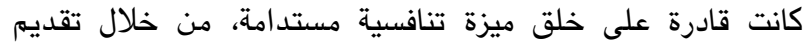

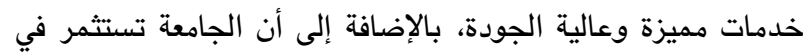

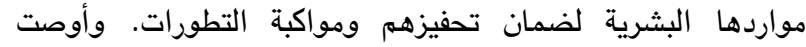

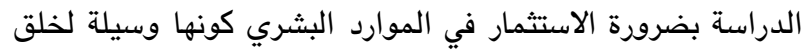
ميزة تنافسية مستدامة.

كما أجرى حسن (Hasan, 2014) دراسة حول تدويل التعليم الجامعي كمدخل لزيادة القدرة التنافسية للجامعات المصرية.

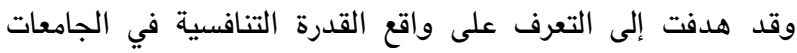

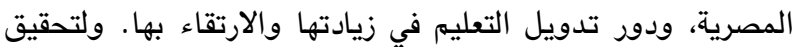

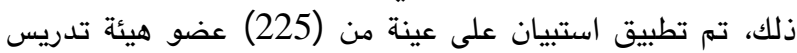

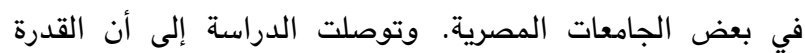

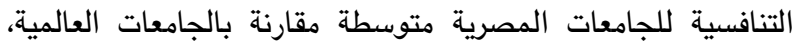

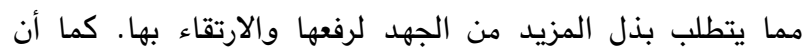

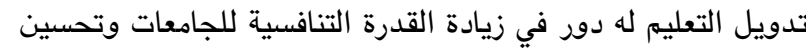

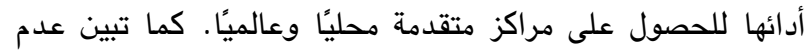

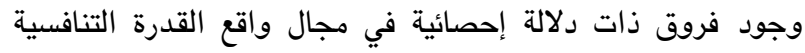

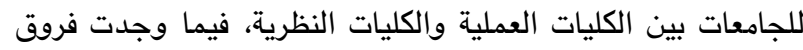

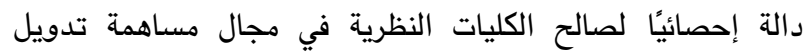

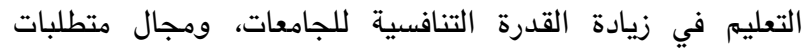

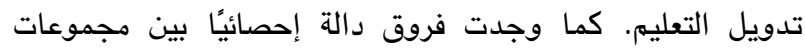

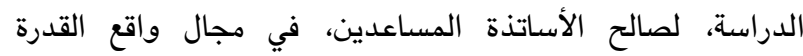

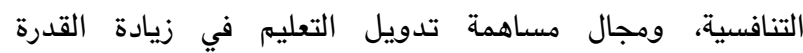

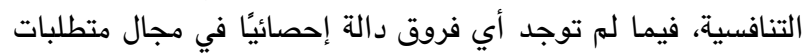

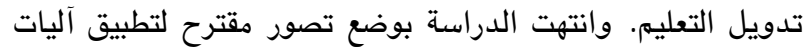
تدويل التعليم في الجامعات المصرية لزيادة قدرتها التنافسية. ودراسة الديحاني (Daihani, 2017) تحت عنوان: تطوير دور التنمية المهنية لأعضاء هيئة التدريس في تحقيق الميزة

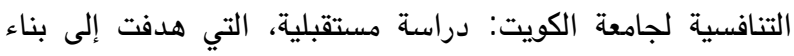

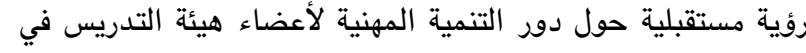

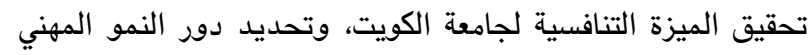

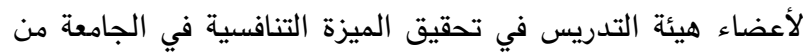

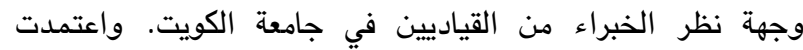

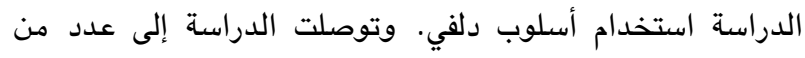

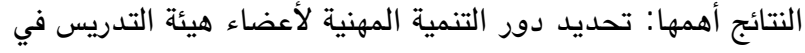

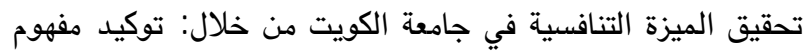

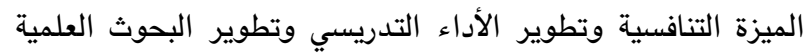

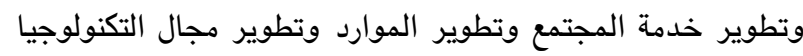

وقد تم إجراء عدد من الدراسات حول هذا الموضوع،

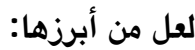

أجرى العامري (Al-Amiri, 2013) دراسة حول متطلبات

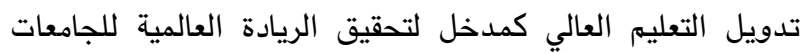

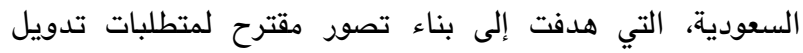

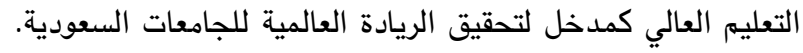

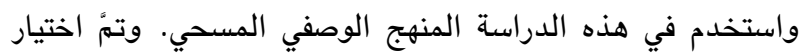

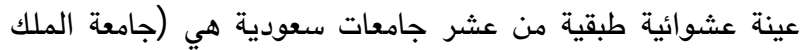

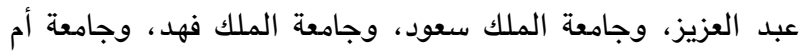

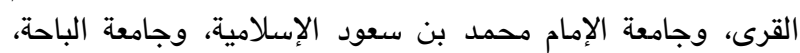

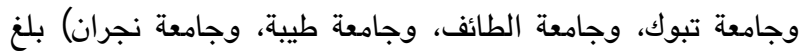

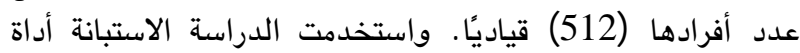

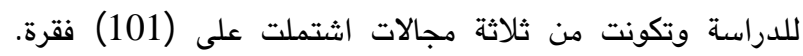

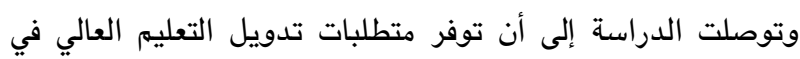

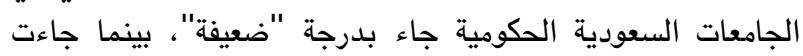

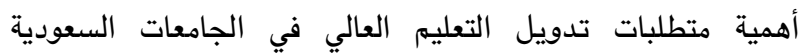

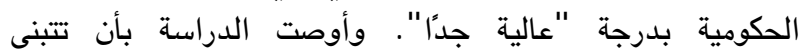

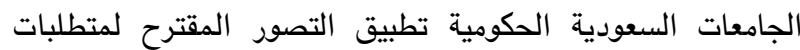

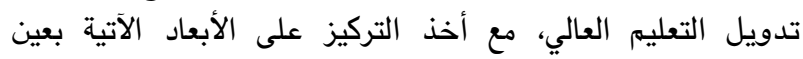

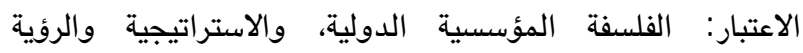
الدولية، والبنية التنظيمية الدولية، والحراك والتنمية المهنية الدولية، والدية الدية الدولية

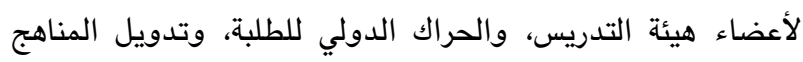

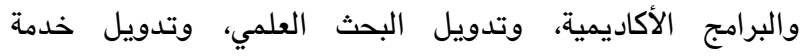
المجتمع، وتمويل أنشطة التدويل، والتسويق التدويل الدولي للجامعات.

وأجرى كاماو (Kamau, 2013) دراسة حول الاستراتيجيات التنافسية التي تتبناها الجامعات الخاصة في كينيا، هدفت إلى تحديد

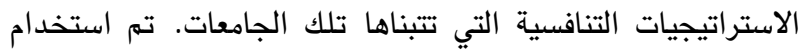

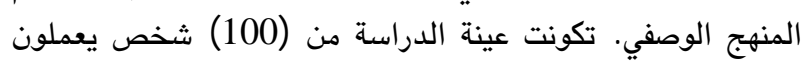

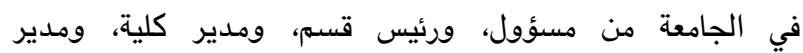

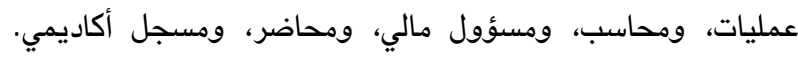

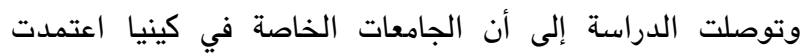

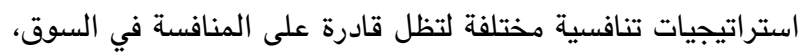

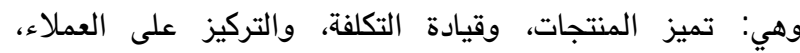

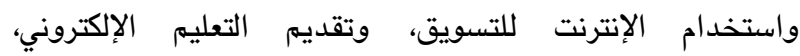

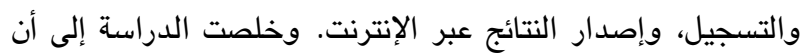

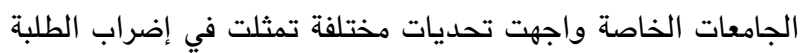

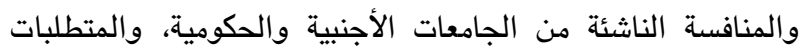

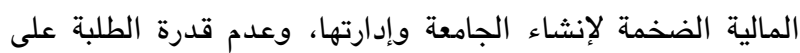

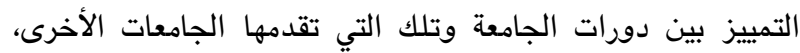

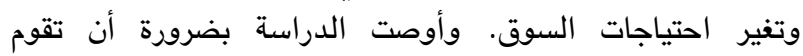
الجامعات بتبني الاستراتيجيات التي تعمل على زيادة الربحية وتقليل

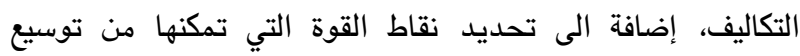
نطاقها داخل سوق الجامعات الخاصة. 
الاهتمام بالتخطيط الاستراتيجي، وغموض الرؤى التي توجهها نحو الميزة التنافسية عالميًا (Al-Amiri, 2013). وقد جاء مشروع نيوم لإنجاز رؤية المملكة (2030)

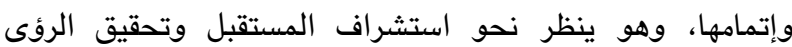

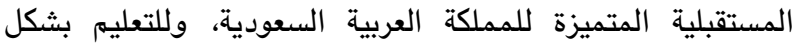

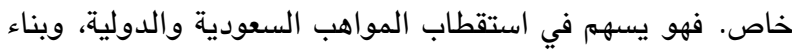

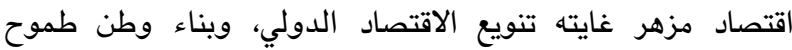

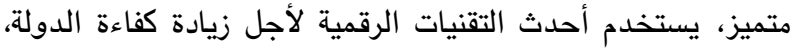

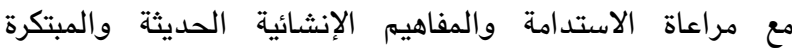
.(Saudi Vision, 2030)

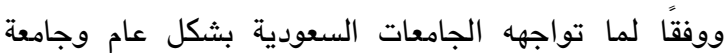
تبوك بشكل خاص من تحديات، فرضتها عليها التنافسية العالمية، فلن تتمكن من تحقيق الميزة التنافسية دون وجود رؤى استراتيجية

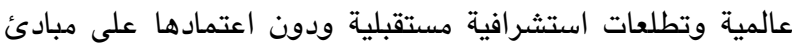
تدويل التعليم العالي، وإضفاء البعد الدولي على أعمالها وأبحاثها

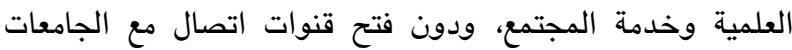

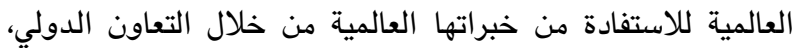

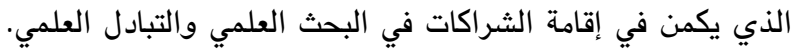

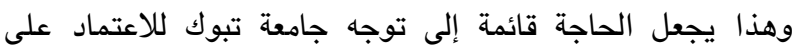

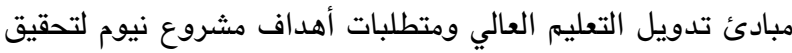

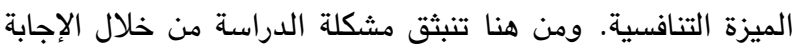

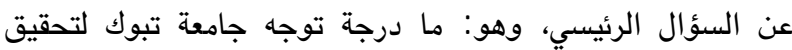

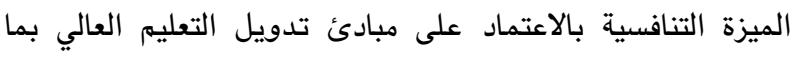
يتوافق مع متطلبات أهداف مشروع نيوم؟ لاعن علئ

وتنبثق عن هذا السؤال الرئيسي الأسئلة الفرعية الآتية: 1. ما المتطلبات اللازمة لتوجه جامعة تبوك لتحقيق الميزة التنافسية بالاعتماد على مبادئ تدويل التعليم العالي بما يتوافق تئق

$$
\text { مع متطلبات أهداف مشروع نيوم؟ }
$$

2. ما معوقات توجه جامعة تبوك لتحقيق الميزة التنافسية بالاعتماد على مبادئ تدويل التعليم العالي بما يتوافق مع متطلبات أهداف مشروع نيوم؟ مائ تدوئ 3. هل هناك فروق ذات دلالة إحصائية في درجة توجه جامعة تبوك

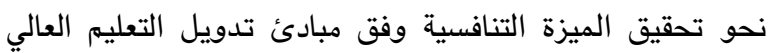

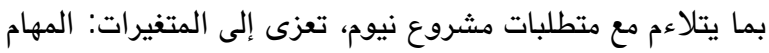

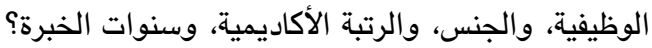

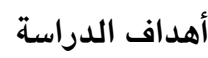

هدفت الدراسة إلى بيان درجة توجه جامعة تبوك لتحقيق

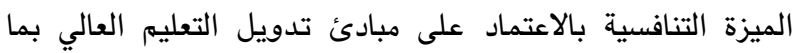
يتوافق مع متطلبات أهداف مشروع نيوم. كما تسعى إلى تحديد معوقات توجه جامعة تبوك لتحقيق الميزة التنافسية بالاعتماد على الى الى

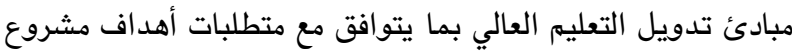

وتطوير إنتاج المعرفة. بالإضافة إلى بناء رؤية مستقبلية لتطوير

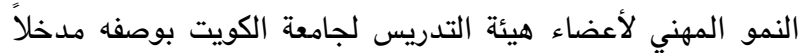
لتحقيق الميزة التنافسية لجامعة الكويت. لأنساء لتربئ وأجرى عبيد الله (Obeidallah, 2017) دراسة حول فاعلية تطبيق معايير الجودة (Baldrige) في التعليم العالي

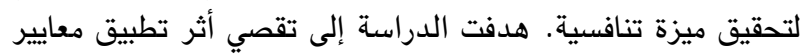

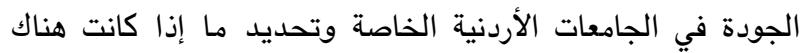

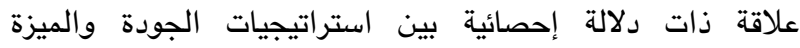

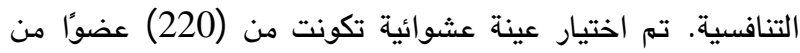

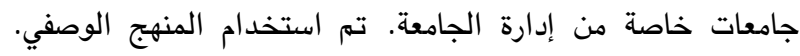

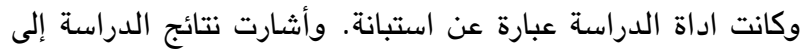

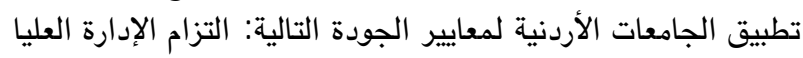

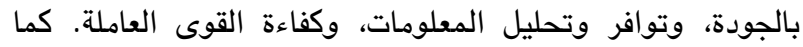

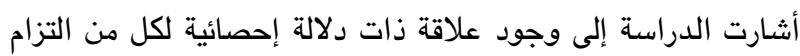

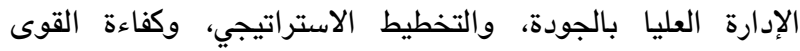

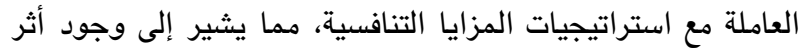

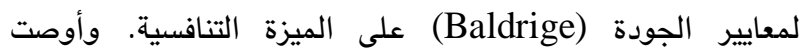

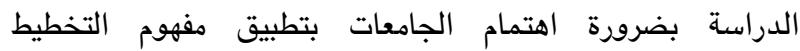

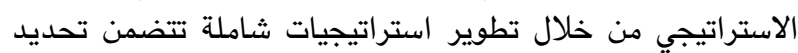
خطوات لتطبيق معايير بالدريج (Baldrige) للجودة.

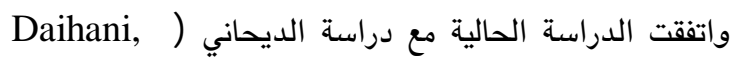

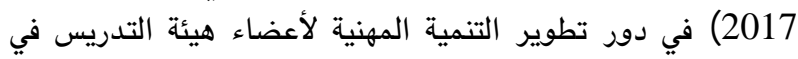

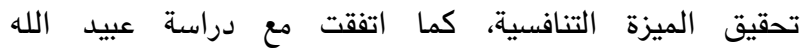
(Obeidallah, 2017)

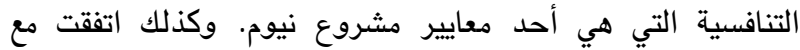

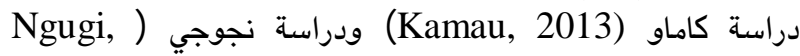

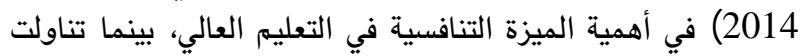

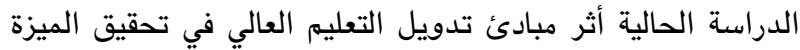

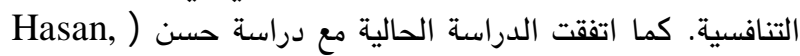

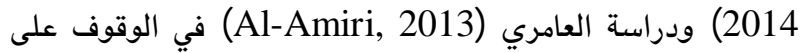

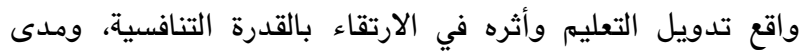
توفر متطلبات تدويل التعليم العالي، وأهمية متطلبات تدويل التعاء التعليم

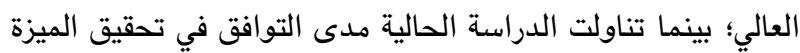

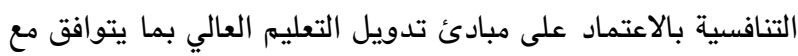

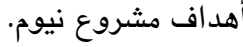

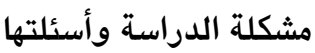

برز توجه الجامعات السعودية نحو تحقيق الميزة التنافسية

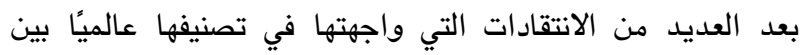

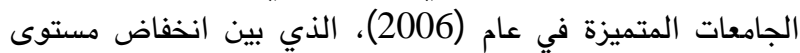

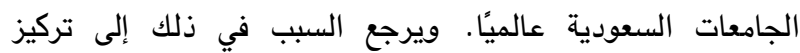
الجامعات السعودية على التعليم وتخريج الكوادر فقط، وإلى فئ عدم إلى تركيز 
حدود الدراسة تناولت الدراسة توجه جامعة تبوك لتحقيق الميزة التنافسية

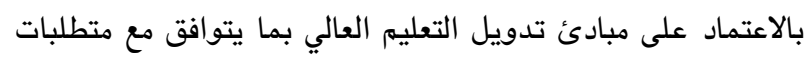

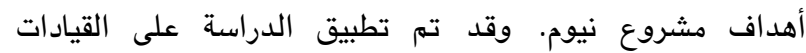
الاكاديمية (عمداء الكليات) في جامعة تبوك. خلال العام الدراسي تلي

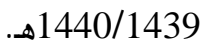

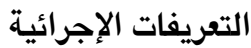

- الميزة التنافسية: هي المركز ذو الأجل البعيد، الذي تهدف

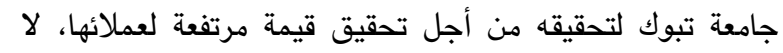

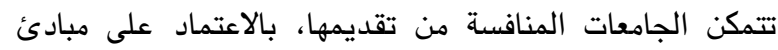

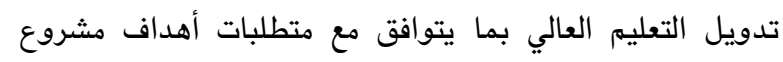

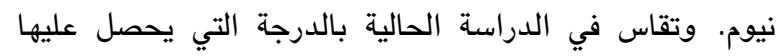

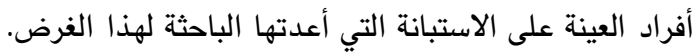
- التدويل: أسلوب لإكساب الطابع الدولي للسياسات والأعمال التي

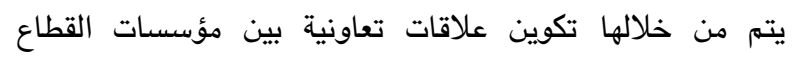

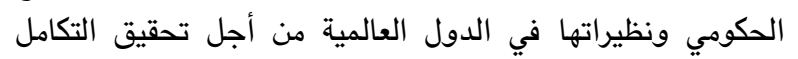
والتشارك والغايات المشتركة بينها.

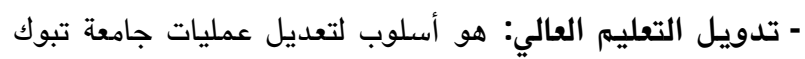

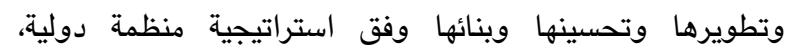

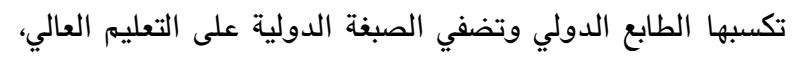

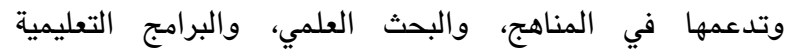

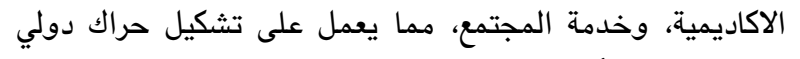

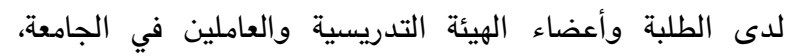

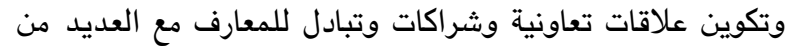

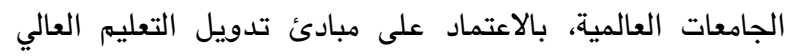

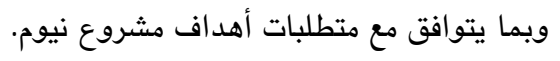

- مشروع نيوم: واجهة خاصة ممتدة بين ثلاث دول تقع شمال

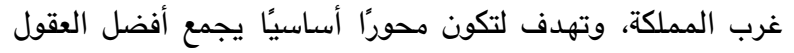

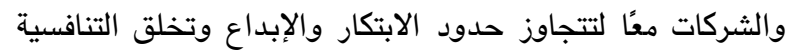

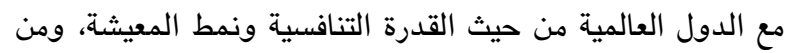
المتوقع أن يكون المشروع أحد المراكز الرائدة في العالم أجمع.

الطريقة

منهج الدراسة

لتحقيق أهداف الدراسة والإجابة عن أسئلتها، استخدمت الباحثة المنهج الوصفي التحليلي. مجتمع الدراسة

تكون مجتمع البحث من جميع القيادات الأكاديمية في جامعة

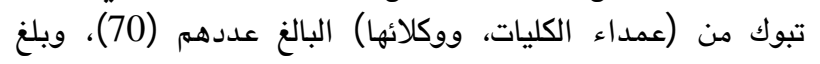
حجم العينة (7.75 \%) من مجتمع الدراسة.
نيوم، إضافة إلى تحديد المتطلبات اللازمة لتوجه جامعة تبوك

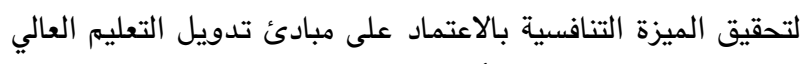

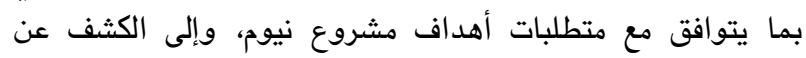

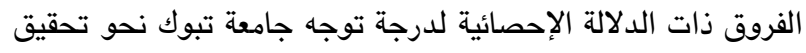

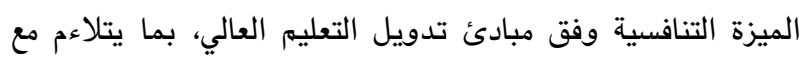

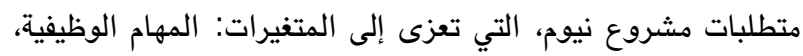
والجنس، والرتبة الأكاديمية، وسنوات الخئون الخبرة.

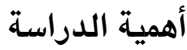

تكمن الأهمية النظرية للدراسة في كونها تُعد إضافة علمية في

مجال الإدارة والتخطيط في المملكة العربية السعودية وفي منطقة

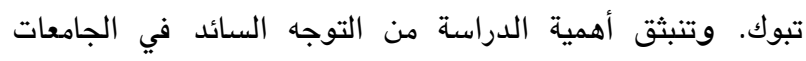

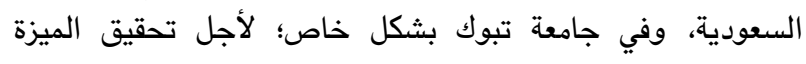

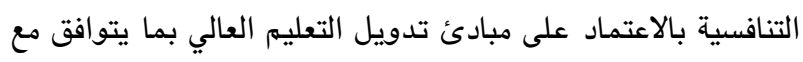

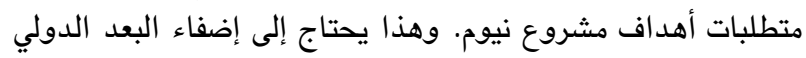

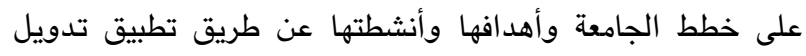

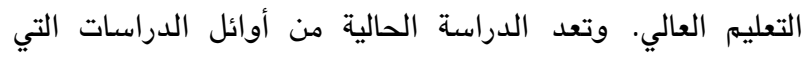

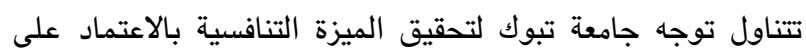

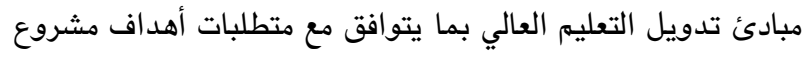

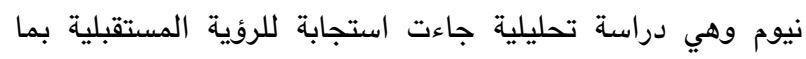

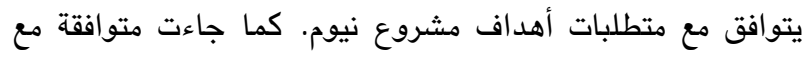

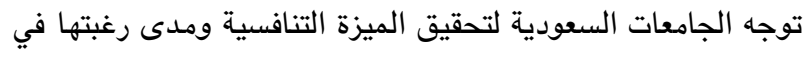

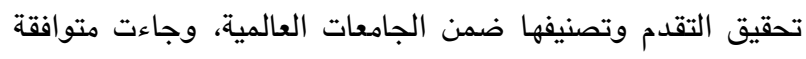

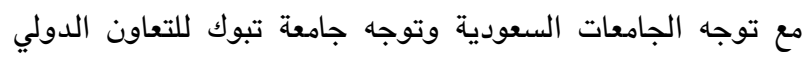

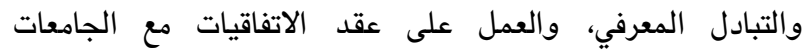

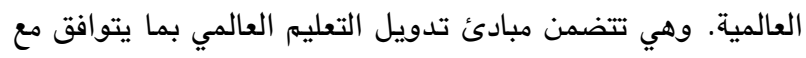

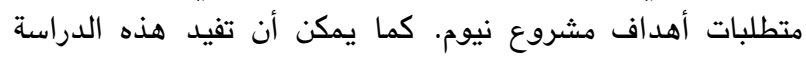

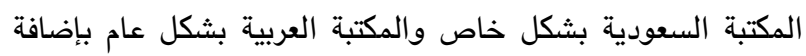

معرفة جديدة.

أما الأهمية العملية (التطبيقية) للدراسة، فتمثل في سعيها

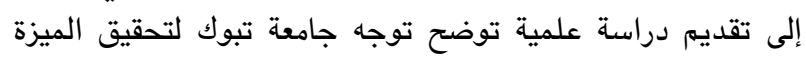

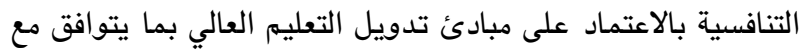

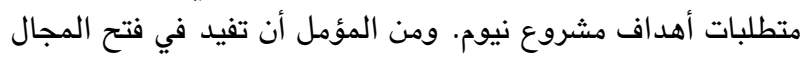

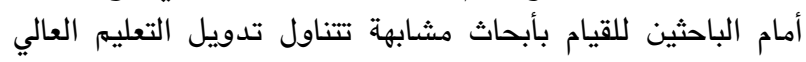

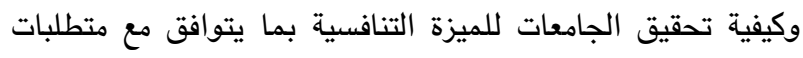

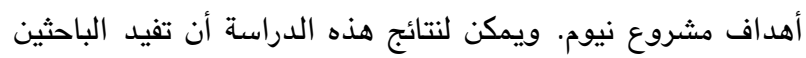

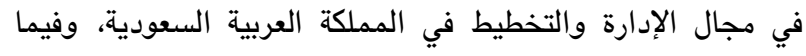

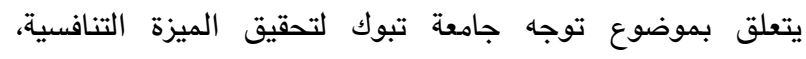

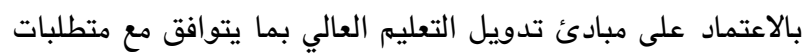

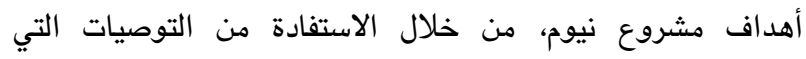
ستخرج بها الدراسة. 
1- معوقات توجه جامعة تبوك لتحقيق الميزة التنافسية بالاعتماد على مبادئ تدويل التعليم العالي بما يتوافق مع متطلبات أهداف بـ بـون مشروع نيوم. 2- درجة توجه جامعة تبوك لتحقيق الميزة التنافسية بالاعتماد على نـ مبادئ تدويل التعليم العالي بما يتوافق مع متطلبات أهداف

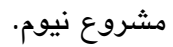
3- المتطلبات اللازمة لتوجه جامعة تبوك لتحقيق الميزة التنافسية

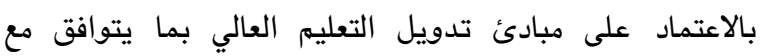
متطلبات أهداف مشروع نيوم. صيغت جميع الفقرات بحيث تدلٌ الدرجة المرتفعة على درجة عالية من توجه جامعة تبوك نحو تحقيق الميزة التنافسية. أما

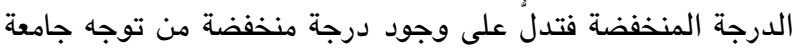
تبوك نحو تحقيق الميزة التنافسية. وتم استخدام مقياس ليكرت دورته (Likert)

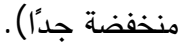

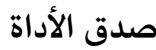

بعد أن تم بناء الاستبانة في صورتها الأولية، تم عرضها

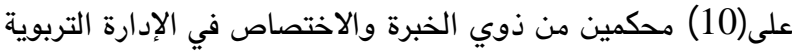
في الجامعات السعودية؛ بهدف معرفة آرائهم وإبداء ملحوظئهاتهاتهم حول مدى وضوح الفقرات وصحتها اللغوية، ومدى سلامة صياغة الفقرات وأنتمائها إلى المجال الذي تندرج الفرات وصتهـه . وبعد جمع آراء

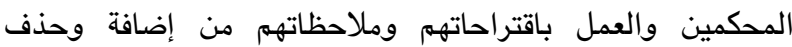
وتعديل ودمج، تم تعديل ما يلزم حسب اتفاق اتفاق المحكمين

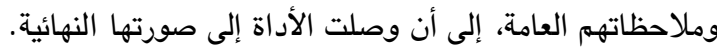

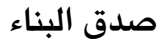

تم التوصل إلى دلالات الصدق الداخلي من خلال تطبيق الاستبانة على عينة عشوائية مكونة من القيادات الأكاديمية في جامعة تبوك، ثم حُسب معامل ارتباط بيرسون بين الدرجة على على ملى مليه

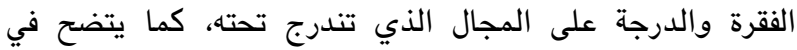

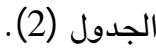

عينة الدراسة

تم اختيار عينة البحث بالطريقة الطبقية العشوائية، وطبقت

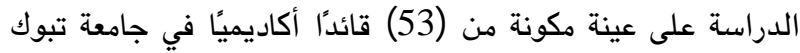

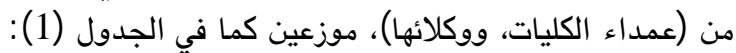
جدول (1): توزيع أفراد العينة حسب المتفيرات

\begin{tabular}{|c|c|c|c|}
\hline النسبة المئوية & التكرار & الفئات & المتغير \\
\hline$\% 32.1$ & 17 & عميد & \multirow{5}{*}{ المهام الوظيفية } \\
\hline$\% 1.9$ & 1 & عميدة & \\
\hline$\% 33.9$ & 18 & وكيل & \\
\hline$\% 32.1$ & 17 & وكيلة & \\
\hline$\% 100$ & 53 & المجموع & \\
\hline$\% 66$ & 35 & زكر & \multirow{3}{*}{ الجنس } \\
\hline$\% 34$ & 18 & أنثى & \\
\hline$\% 100$ & 53 & المجموع & \\
\hline$\% 3.8$ & 2 & أستان & \multirow{4}{*}{ الرتبة الأكاديمية } \\
\hline$\% 32.1$ & 17 & استاذ مشارك & \\
\hline$\% 64.1$ & 34 & استاذ مساعد & \\
\hline$\% 100$ & 53 & المجموع & \\
\hline$\% 0$ & 0 & أقل من سنة & \multirow{5}{*}{ سنوات الخبرة } \\
\hline$\% 0$ & 0 & من 1 - اقل من 5 & \\
\hline$\% 67.9$ & 36 & من 5 - 10 سنوات & \\
\hline$\% 32.1$ & 17 & أكثر من 10 سنوات & \\
\hline$\% 100$ & 53 & المجموع & \\
\hline
\end{tabular}

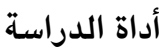

تم استخدام الإستبانة لجمع البيانات، وتم إعداد الاستبانة بعد

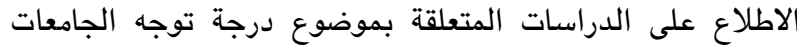
نحو تحقيق الميزة التنافسية وفق مبادئ تدويل التعليم العالي بما يتلاءم مع متطلبات مشروع نيوم، بعدها تمت صياغة الفقرات التي

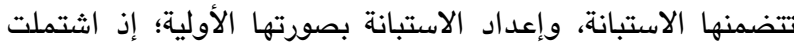
على (31) فقرة تندرج تحت ثلاثة مجالات:

جدول (2): معاملات ارتباط بيرسون للفقرات مع المجال الذي تندرج تحته

\begin{tabular}{|c|c|c|c|c|c|}
\hline \multicolumn{2}{|c|}{ المجال الثالث } & \multicolumn{2}{|c|}{ المجال الثاني } & \multicolumn{2}{|c|}{ المجال الأول } \\
\hline معامل الارتباط & رقم الفقرة & معامل الارتباط & رقم الفقرة & معامل الارتباط & رقم الفقرة \\
\hline $0.831 * *$ & 1 & $0.896 * *$ & 1 & $0.896 * *$ & 1 \\
\hline $0.813 * *$ & 2 & $0.885 * *$ & 2 & $0.885 * *$ & 2 \\
\hline $0.875 * *$ & 3 & $0.605 * *$ & 3 & $0.605 * *$ & 3 \\
\hline $0.838 * *$ & 4 & $0.780 * *$ & 4 & $0.780 * *$ & 4 \\
\hline $0.875 * *$ & 5 & $0.913 * *$ & 5 & $0.831 * *$ & 5 \\
\hline $0.838 * *$ & 6 & $0.901 * *$ & 6 & $0.813 * *$ & 6 \\
\hline $0.590 * *$ & 7 & $0.800 * *$ & 7 & $0.875 * *$ & 7 \\
\hline $0.672 * *$ & 8 & $0.869 * *$ & 8 & $0.838 * *$ & 8 \\
\hline $0.875 * *$ & 9 & $0.790 * *$ & 9 & $0.590 * *$ & 9 \\
\hline $0.590 * *$ & 10 & & & $0.672 * *$ & 10 \\
\hline & & & & $0.488 * *$ & 11 \\
\hline
\end{tabular}


والمجال الثالث تتراوح بين (0.590- 0.875)، وهي قيم دالة إحصائيًا عند مستوى الدلالة (0.01) .

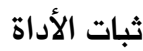

للتوصل إلى دلالات ثبات أداة الدراسة، تم استخدام معادلة

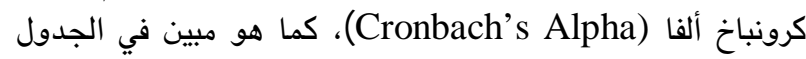

يظهر من الجدول (2) أن معاملات الارتباط بين الدرجة على

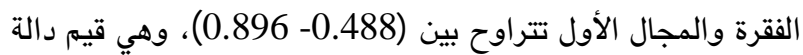
إحصائيًا عند مستوى الدلالة (0.01). كما أن معاملات الارتباط

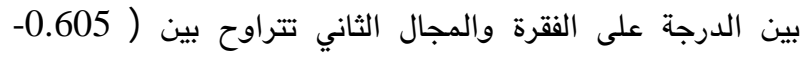

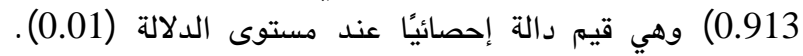
كذلك يظهر الجدول أن معاملات الارتباط بين الدرجة على الفقرة الدلا

جدول (3): معامل كرونباخ ألفا لأداة الدراسة

\begin{tabular}{|c|c|c|}
\hline معامل كرو نباخ الفا & عدد الفقرات & المجال \\
\hline 0.95 & 11 & 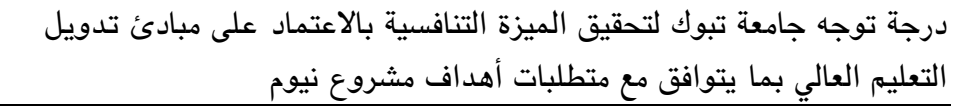 \\
\hline 0.935 & 9 & التعليم العالي بما يتوافق معات تبوك لتحقيق الميزة التنافسية بالاعتماد على مبادئ تدويل \\
\hline 0.846 & 10 & 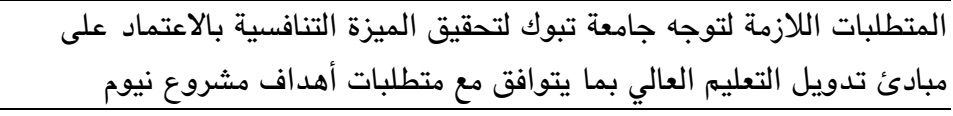 \\
\hline 0.835 & 30 & الأداة ككل \\
\hline
\end{tabular}

يظهر من الجدول (3) أن معامل كرونباخ ألفا لمجالات النتائج

1- النتائج المتعلقة بالإجابة عن السؤال الأول: ما درجة توجه

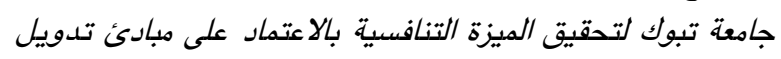

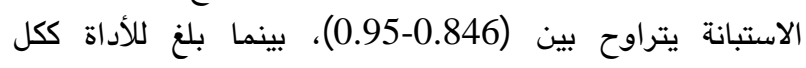

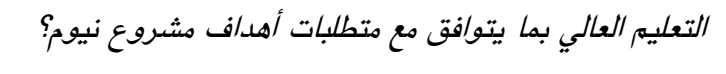
(0.835)، وهي قيم مناسبة لأغراض الدراسة الحالية. التصحيح للإجابة عن هذا السؤال، تم حساب المتوسطات الحسابية

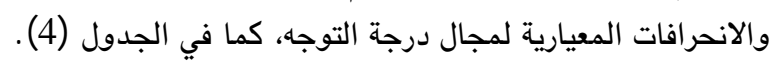
تمت الإجابة عن كل فقرة وفق مقياسٍ ليكرت الخماسي، وقد

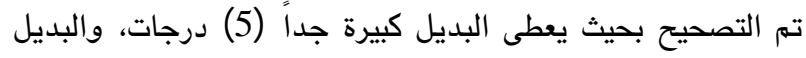

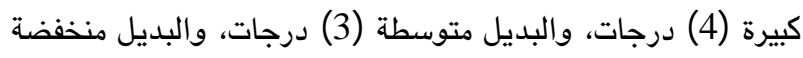
درجتين، والبديل منخفضة جدًا والبد متدة.

جدول (4): المتوسطات الحسابية والانحرافات المعيارية لمجال درجة التوجه

\begin{tabular}{|c|c|c|c|c|}
\hline 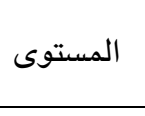 & 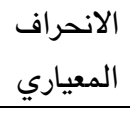 & 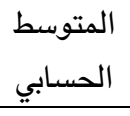 & 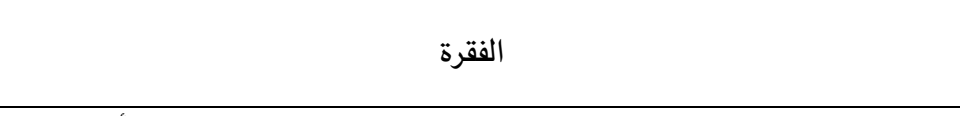 & 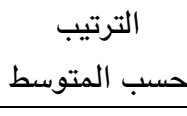 \\
\hline مرتفع جدًا & 0.65 & 4.26 & و تعطي الجامعة للطالب الموهوب فرصة التنافس العالمي للمشاركة في الأنشطة & 1 \\
\hline 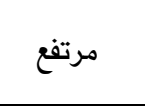 & 0.81 & 4.09 & تسعى الجامعة إلى تحقيق التنافسية من خلال الاطلاع على استراتيجيات التغيير & 2 \\
\hline 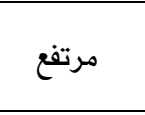 & 0.48 & 4.00 & و تتيح الجامعة فرصًا ريادية لأعضاء هيئة التدريس للمشاركة في الندوات & 3 \\
\hline 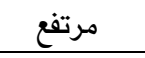 & 1.08 & 3.92 & تطبق الجامعة المعايير العالمية لجودة التعليم والبحث العلمي. & 4 \\
\hline 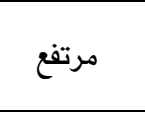 & 0.89 & 3.66 & رؤنافية الجامعة ورسالتها تركزان على تطبيق مفهوم التدويل من أجل تعزيز قدرتها & 5 \\
\hline 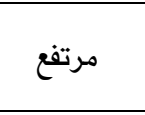 & 1.05 & 3.64 & مشروع نيوم. تفعل الجامعة التوأمة مع الجامعات العالمية المرموقة بما يتناسب وتحقيق أهداف & 6 \\
\hline 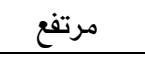 & 0.91 & 3.49 & سياسة التعليم في جامعة تبوك تعكس مفهوم الريادة في التعليم. & 7 \\
\hline
\end{tabular}




\begin{tabular}{|c|c|c|c|c|}
\hline 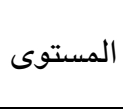 & الالحعراف & الحسابي & الفقرة & حسب المتوسط \\
\hline متوسط & 0.76 & 3.37 & خطط الجامعة الاستراتيجية تركز على البعد العالمي ومغامرة التنافسية العالمية. & 8 \\
\hline 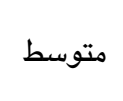 & 0.86 & 3.22 & لدعمر الجامعة بنية تحتية ذات معايير عالمية لتطوير الابتكارات البحثية والإبداعية & 9 \\
\hline متوسط & 1.06 & 3.11 & توجد مشاركات عالمية للجامعة على المستوى العلمي والبحثي. & 10 \\
\hline متوسط & 0.66 & 3.11 & تطبق الجامعة الممارسات العالمية السائدة في الجامعات المتقدمة. & 11 \\
\hline مرتفع & 0.72 & 3.62 & المتوسط العام & \\
\hline
\end{tabular}

2- النتائج المتعلقة بالإجابة عن السؤال الثاني: ما معوقات توجه

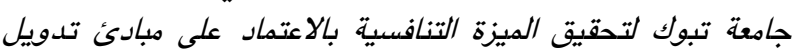
التعليم العالي بما يتوافق مع متطلبات أهداف مشروع نيوم؟ لاعتئ للإجابة عن هذا السؤال، تم حساب المتوسطات الحسابية والانحرافات المعيارية لإجابات أفراد عينة الدراسة لمجال المالية المعوقات،

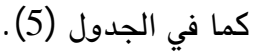

يثير الجدول (4) إلى أن أكبر متوسط حسابي كان للفقرة

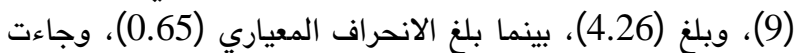

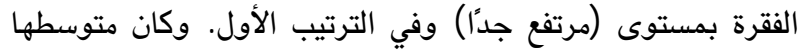

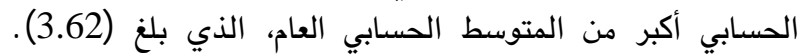

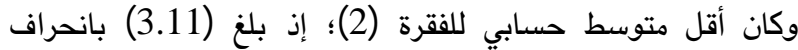

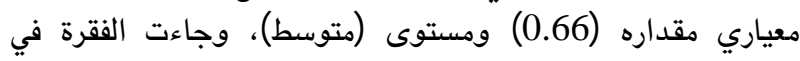
الترتيب (11)، وكان متوسطها الحسابي أقل من المتوسط الحساءي الحسابي

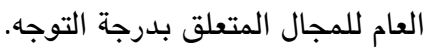

جدول (5): المتوسطات الحسابية والانحرافات المعيارية لمجال المعوقات

\begin{tabular}{|c|c|c|c|c|}
\hline 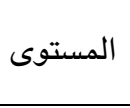 & 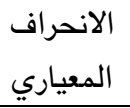 & 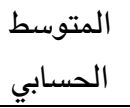 & 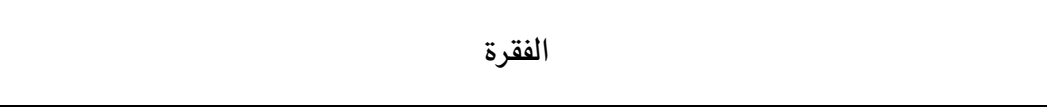 & 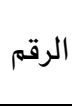 \\
\hline 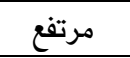 & 0.95 & 4.32 & المناهج لا يتم تحديثها وفق متطلبات أهداف مشروع نيوم. & 2 \\
\hline 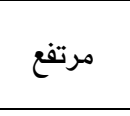 & 0.95 & 4.31 & نيوم. عدم تطوير الأنظمة الأكاديمية والإدارية بما يتوافق مع تدويل التعليم واهدف مشروع & 1 \\
\hline 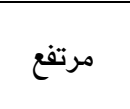 & 1.01 & 4.04 & أو أنثطة البحث العلمي أو أساليب التعله. & 7 \\
\hline 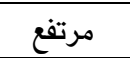 & 1.03 & 4.03 & ضعف الدعم المادي الموجه نحو تدويل التعليم وتحقيق نظام تعليمي عالمي. & 5 \\
\hline 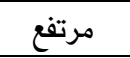 & 0.75 & 4.00 & تفتقد الجامعة البنية التحتية ذات المعايير العالمية لتطوير الابتكارات البحثية. & 9 \\
\hline 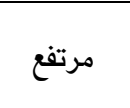 & 0.91 & 3.92 & ضعالمية. مشاركة أعضاء هيئة التدريس في المؤتمرات الدولية التي ترعاها الجامعات & 3 \\
\hline 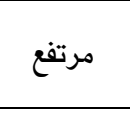 & 1.08 & 3.60 & وتتلاءم مع متطلبات مشروع نبوك وجود خطط واستراتيجيات شاملة وواضحة وهادفة لتدويل التعليم & 6 \\
\hline 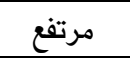 & 1.30 & 3.58 & ضعف قدرات طلاب الجامعة للمنافسة في الأنشطة الطلابية العالمية. & 4 \\
\hline 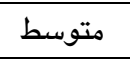 & 1.00 & 3.28 & ضعف قنوات التواصل مع الجامعات العالمية مما أضعف مستوى التنافسية لدى الجامعة. & 8 \\
\hline 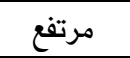 & 0.82 & 3.90 & المتوسط العام & \\
\hline
\end{tabular}

3- النتائج المتعلقة بالإجابة عن السؤال الثالث: ما المتطلبات

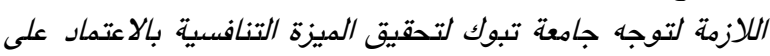

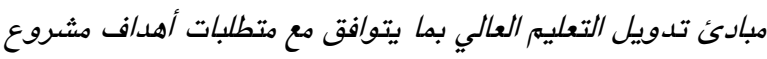
نيوم؟ - ن

تم حساب المتوسطات الحسابية والانحرافات المعيارية لإجابات أفراد عينة الدراسة لمجال درجة الموافقة على المتطلبات،

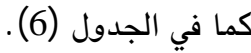

يشير الجدول (5) إلى أن أكبر متوسط حسابي كان للفقرة

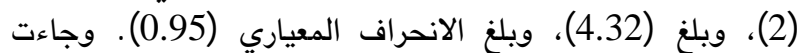

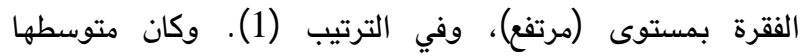

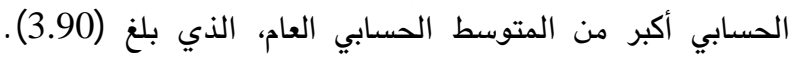

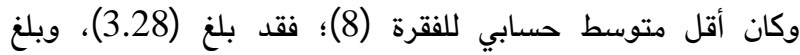

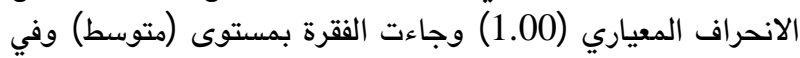

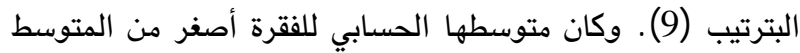
الحسابي العام لمجال المعوقات. 
جدول (6): المتوسطات الحسابية والانحرافات المعيارية لمجال الموافقة على المتطلبات

\begin{tabular}{|c|c|c|c|c|}
\hline 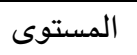 & الانحراف المعياري & المتوسط الحسابي & 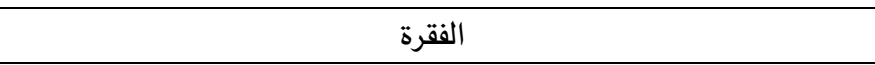 & 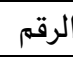 \\
\hline 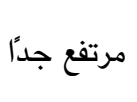 & 0.50 & 4.56 & العالمية التي نادى بها مشروق الدقيق نيوم. التنافية من خلال تطبيقها للتوجهات & 10 \\
\hline مرتفع جداً & 0.50 & 4.55 & داخل الجامعة. بورة تية تحتية ذات معايير عالمية لتطوير الابتكارات البحثية & 9 \\
\hline 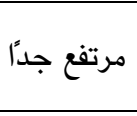 & 0.50 & 4.54 & في تحقيق أهداف مشروع نيوم لدعبيق فكرة نظام تعليمي عالمي يسهم مستقبلاً & 7 \\
\hline مرتفع جدًا & 0.50 & 4.52 & إشراك الطلاب في أنشطة عالمية لتفعيل دورهم في تحقيق مشروع نيوم. & 6 \\
\hline 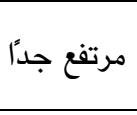 & 0.50 & 4.51 & تفعيل دور أعضاء هيئة التدريس في دعمم التدويل في التعليم من خلال & 5 \\
\hline 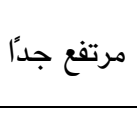 & 0.69 & 4.43 & 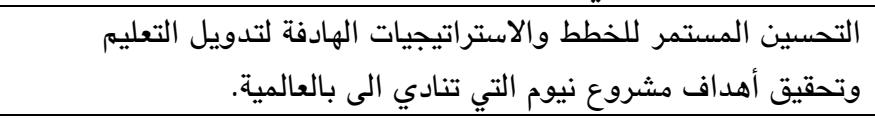 & 8 \\
\hline مرتفع جداً & 0.65 & 4.26 & تحتطلبث رسالة الجامعة ورؤيتها وفق ما يقتضيه التدويل في التعليم & 3 \\
\hline 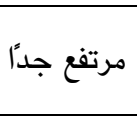 & 0.65 & 4.26 & تحفيق المتطلبات المادية والبشرية والإدارية التي تسهمه في إنجاح تطبيق & 2 \\
\hline مرتفع جداً & 0.79 & 4.20 & تضمين المناهج والخطط الدراسية البعد العالمي والدولي. & 4 \\
\hline 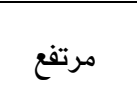 & 0.86 & 4.05 & التعليمه نحو فتح قنوات للتواصل مع الجامعات الرائدة في مجال تدويل & 1 \\
\hline مرتفع جداً & 0.40 & 4.39 & المتوسط العام & \\
\hline
\end{tabular}

متطلبات مشروع نيوم تعزى إلى المتغيرات: المهام الوظيفية،

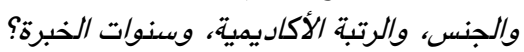

للإجابة عن هذا السؤال، تم إجراء اختبار ت وتحليل التباين

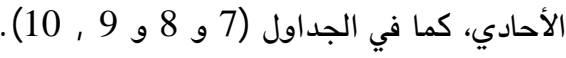

أولاً: متفير المهام الوظيفية

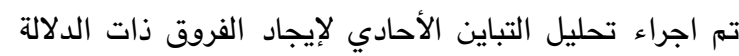

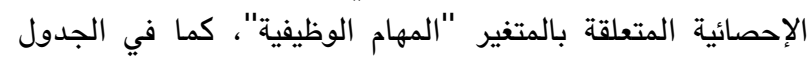

يثير الجدول (6) إلى أن أكبر متوسط حسابي للفقرة كان

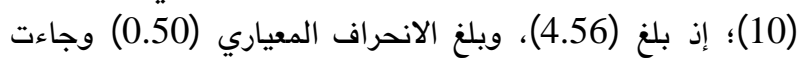

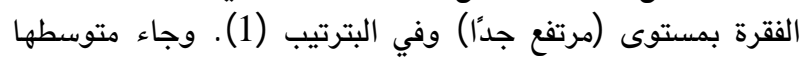

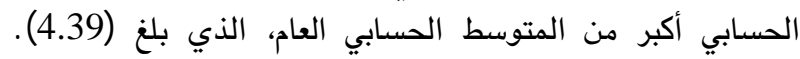

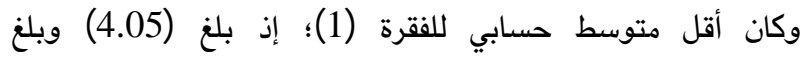
الانحراف المعياري (0.86) . وجاءت الفترسي الفقرة بمستوى (مرتفع) وفي

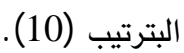

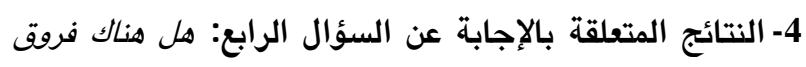

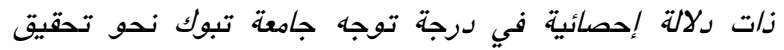

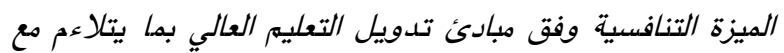

جدول (7): نتائج تحليل التباين الأحادي المتعلقة بالمتفير "المهام الوظيفية"

\begin{tabular}{|c|c|c|c|c|c|c|}
\hline مستوى الدلالة & قيمة ف & متوسط المربعات & درجات الحرية & مجموع المربعات & مصدر التباين & المجال \\
\hline \multirow{3}{*}{0.241} & \multirow{3}{*}{1.445} & 0.736 & 3 & 2.208 & بين المجموعات & \multirow{3}{*}{ التوجه } \\
\hline & & 0.509 & 49 & 24.954 & داخل المجموعات & \\
\hline & & & 52 & 27.161 & المجموع & \\
\hline \multirow{3}{*}{0.946} & \multirow{3}{*}{0.124} & 0.088 & 3 & 0.265 & بين المجموعات & \multirow{3}{*}{ المعوقات } \\
\hline & & 0.714 & 49 & 34.985 & داخل المجموعات & \\
\hline & & & 52 & 35.251 & المجموع & \\
\hline \multirow{3}{*}{0.760} & \multirow{3}{*}{0.392} & 0.068 & 3 & 0.203 & بين المجموعات & \multirow{3}{*}{ لمتطلبات } \\
\hline & & 0.173 & 49 & 8.457 & داخل المجموعات & \\
\hline & & & 52 & 8.659 & المجموع & \\
\hline
\end{tabular}


يظهر من الجدول (7) عدم وجود فروق ذات دلالة احصائية انيًا: متفير الرتبة الاكاديمية

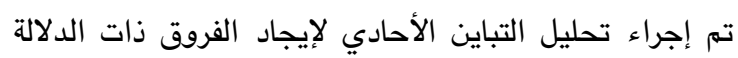

في جميع مجالات الاستبانة تعزى إلى متغير المهام الوظيفية.

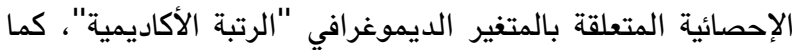

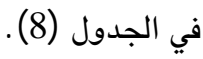

جدول (8): نتائج تحليل التباين الأحادي المتعلقة بالمتغير "الرتبة الأكاديمية"

\begin{tabular}{|c|c|c|c|c|c|c|}
\hline مستوى الدلالة & قيمة ف & متوسط المربعات & درجات الحرية & مجموع المربعات & مصدر التباين & المجال \\
\hline \multirow{3}{*}{0.199} & \multirow{3}{*}{1.666} & 0.849 & 2 & 1.697 & بين المجموعات & \multirow{3}{*}{ التوجه } \\
\hline & & 0.509 & 50 & 25.464 & داخل المجموعات & \\
\hline & & & 52 & 27.161 & المجموع & \\
\hline \multirow{3}{*}{0.547} & \multirow{3}{*}{0.611} & 0.421 & 2 & 0.841 & بين المجموعات & \multirow{3}{*}{ المعوقات } \\
\hline & & 0.688 & 50 & 34.410 & داخل المجموعات & \\
\hline & & & 52 & 35.251 & المجموع & \\
\hline \multirow{3}{*}{0.383} & \multirow{3}{*}{0.978} & 0.163 & 2 & 0.326 & بين المجموعات & \multirow{3}{*}{ المتطلبات } \\
\hline & & 0.167 & 50 & 8.333 & داخل المجموعات & \\
\hline & & & 52 & 8.659 & المجموع & \\
\hline
\end{tabular}

ثالثًا: متغير الجنس

تم إجراء اختبار ت لإيجاد الفروق ذات الدلالة الإحصائية

يظهر من الجدول (8) عدم وجود فروق ذات دلالة احصائية

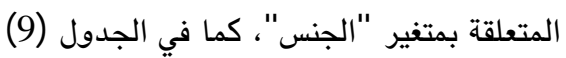

في جميع مجالات الاستبانة تعزى إلى متغير الرتبة الأكاديمية.

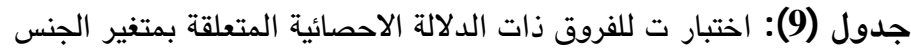

\begin{tabular}{|c|c|c|c|c|c|c|}
\hline مستوى الدلالة & قيمة ت & درجات الحرية & الانحراف المعياري & المتوسط الحسابي & مصدر التباين & المجال \\
\hline \multirow{2}{*}{0.658} & \multirow{2}{*}{0.446} & \multirow{2}{*}{52} & 0.40 & 4.41 & ذكر & \multirow{2}{*}{ التوجه } \\
\hline & & & 0.43 & 4.36 & أنثى & \\
\hline \multirow{2}{*}{0.400} & \multirow{2}{*}{0.848} & \multirow{2}{*}{52} & 0.68 & 3.68 & ذكر & \multirow{2}{*}{ المعوقات } \\
\hline & & & 0.79 & 3.51 & أنثى & \\
\hline \multirow{2}{*}{0.537} & \multirow{2}{*}{0.621} & \multirow{2}{*}{52} & 0.83 & 3.85 & ذكر & \multirow{2}{*}{ المتطلبات } \\
\hline & & & 0.80 & 4.00 & أنثى & \\
\hline
\end{tabular}

يظهر من الجدول (9) عدم وجود فروق ذات دلالة احصائية رابعًا: متفير سنوات الخبرة

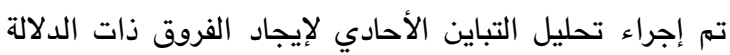

في جميع مجالات الاستبانة تعزى إلى متغير الجنس.

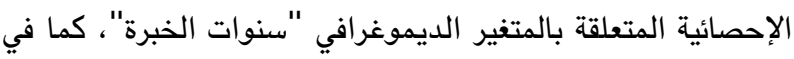

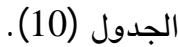

\begin{tabular}{|c|c|c|c|c|c|c|}
\hline مستوى الدلالة & قيمة ف & متوسط المربعات & درجات الحرية & مجموع المربعات & مصدر التباين & المجال \\
\hline \multirow{3}{*}{0.754} & \multirow{3}{*}{0.100} & 0.053 & 1 & 0.053 & بين المجموعات & \multirow{3}{*}{ التوجه ل } \\
\hline & & 0.532 & 51 & 27.108 & داخل المجموعات & \\
\hline & & & 52 & 27.161 & المجموع & \\
\hline \multirow{3}{*}{0.482} & \multirow{3}{*}{0.502} & 0.344 & 1 & 0.344 & بين المجموعات & \multirow{3}{*}{ المعوقات } \\
\hline & & 0.684 & 51 & 34.907 & داخل المجموعات & \\
\hline & & & 52 & 35.251 & المجموع & \\
\hline \multirow{3}{*}{0.601} & \multirow{3}{*}{0.278} & 0.047 & 1 & 0.047 & بين المجموعات & \multirow{3}{*}{ المتطلبات } \\
\hline & & 0.169 & 51 & 8.612 & داخل المجموعات & \\
\hline & & & 52 & 8.659 & المجموع & \\
\hline
\end{tabular}




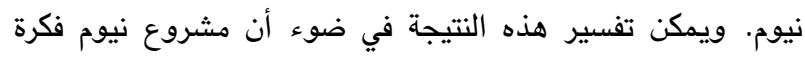

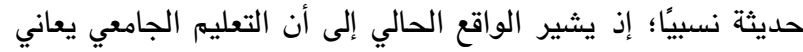

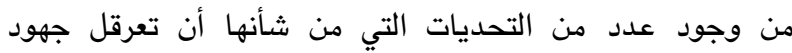

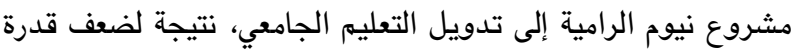

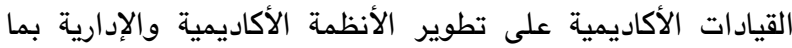

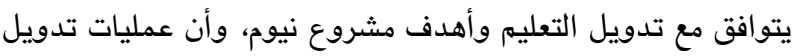

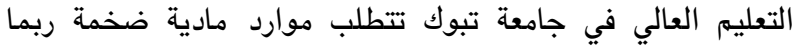

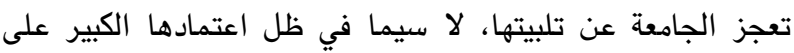

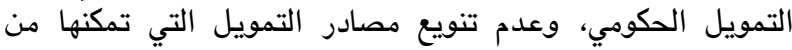
تخصيص الموارد المادية لهذا المشروع. ويشير الواقع أيضًا إلى الى مثلى

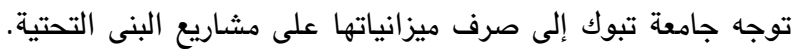

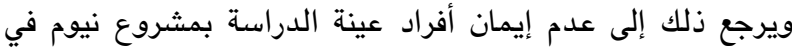

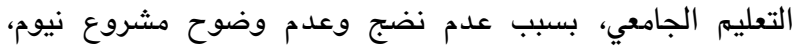

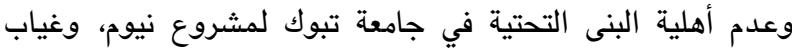
القيادات الكفؤة التي يمكن أن تقود مشروع نيوم. ويعود أيضًا ذلك الك الكيات

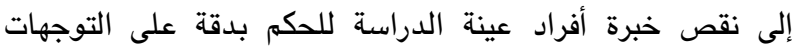

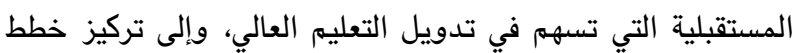

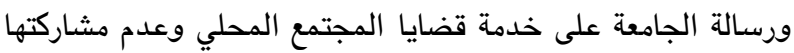

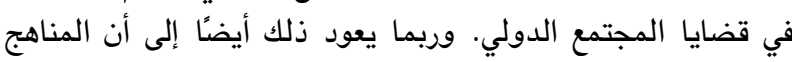

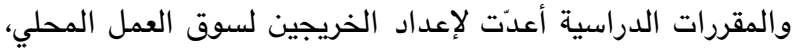

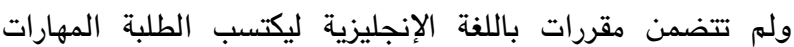
اللازمة لسوق عمل يتصف بالدولية والعالمية.

ويمكن إرجاع هذه النتيجة إلى غياب الخطط والاستراتيجيات

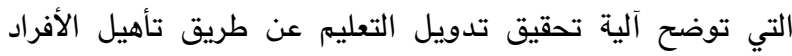

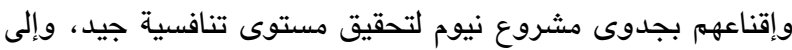

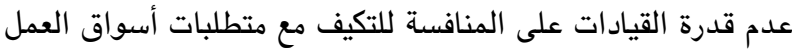

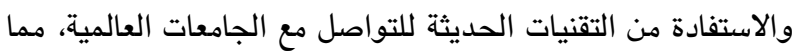

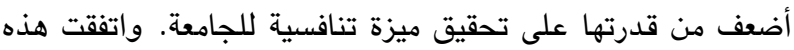

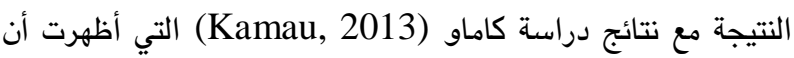

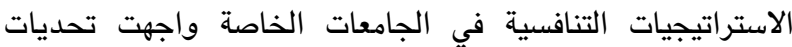

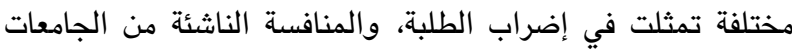

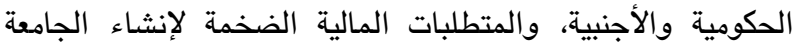
وإدارتها، وعدم قدرة الطلاب على التمييز بين الدور الذي تلؤديه الأديه الجامعة وتلك التي تتؤديها الجامعات الأخرى.

وأظهرت النتائج المتعلقة بالسؤال الثالث أن جامعة تبوك

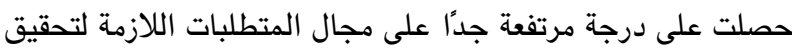

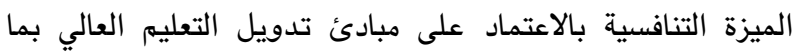

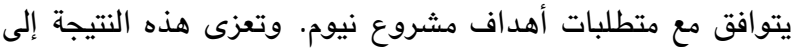

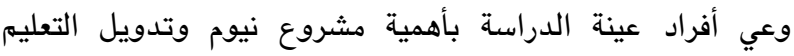

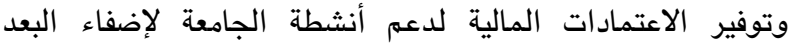

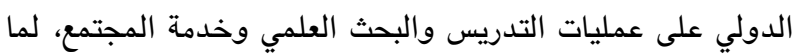

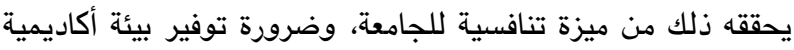

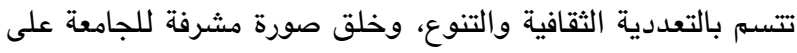

يظهر من الجدول (10) عدم وجود فروق ذات دلالة إحصائية في جميع المجالات تعزى إلى متغير سنوات الخبرة.

مناقشة النتائج

أظهرت نتائج الدراسة المتعلقة بالسؤال الأول أن جامعة تبوك

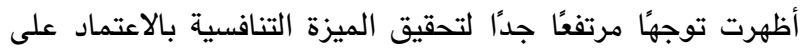

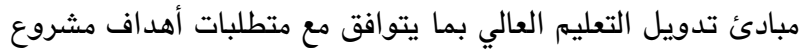

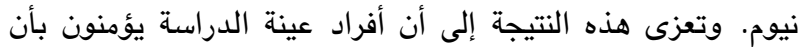

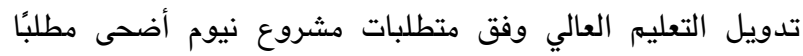

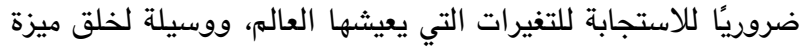
تنافسية. كما أنه الوسيلة الوحيدة لتأسيس قاعدة تعلية التيمية وبحثية،

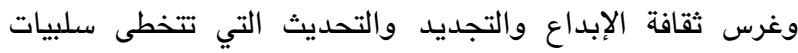

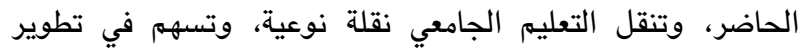
المعرفة والتحول إلى اقتصاد المعرفة.

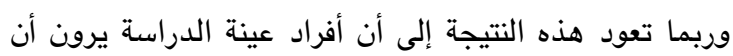

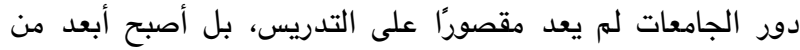

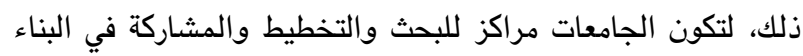

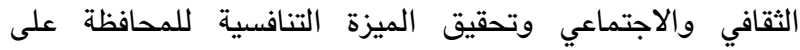

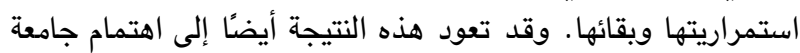

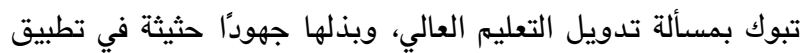

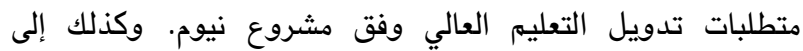

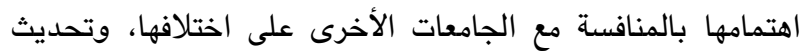
الخطط الدراسية، واستقطاب الخبراء، واستقطاب الطلبة، واهتمامها الخافيا

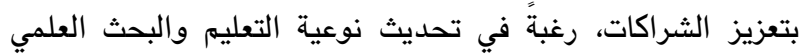

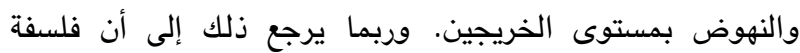
جامعة تبوك تركز على المعطيات المعاصرة والتغيرات التقنية

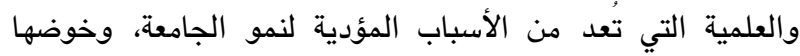

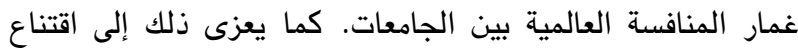

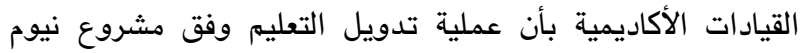

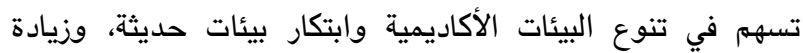
فرص التعلم وفرص انتقال الطلبة، وزيادة حركة أعضاء هيئة التانية

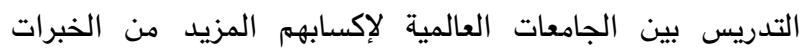
والمعارف التي تعود بالنفع على الجامعة.

ويمكن تفسير هذه النتيجة في ضوء وعي أفراد عينة الدراسة

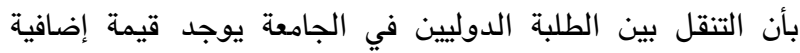
لديها، وذلك بتحقيق مكاسب مالية للجامعة، تكمن في زيادة التية

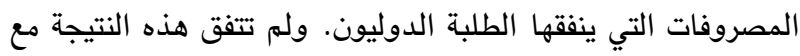
نتائج دراسة حسن (Hasan, 2014) التي أظهرت أن القدرة

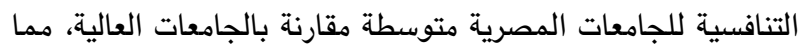

يتطلب ضرورة بذل المزيد من الجهد لرفعها والارتقاء بها.

كما أظهرت النتائج المتعلقة بالسؤال الثاني أن جامعة تبوك

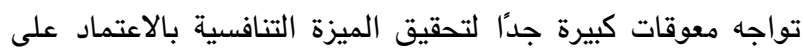

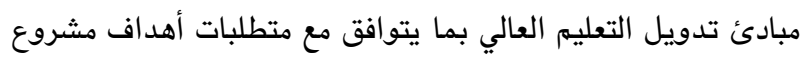


متطلبات تدويل التعليم العالي في الجامعات السعودية الحكومية تبعًا

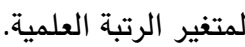

كما كثفت نتائج الدراسة عدم وجود فروق ذات دلالة

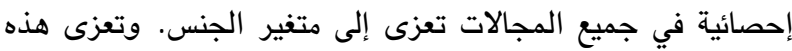

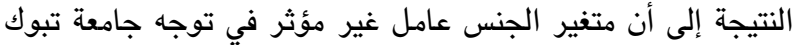

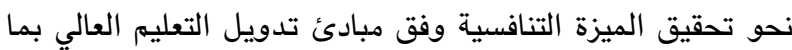

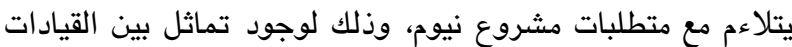
الأكاديمية في جامعة تبوك من حيث طبيعة المهام والمسؤوليات والحقوق، بغض النظر عن الجنس. ولهم تتفق هذه النتيجة مع نتائج

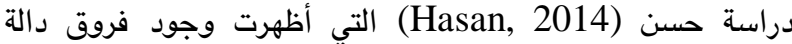

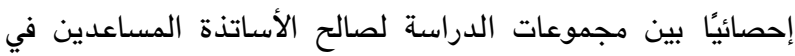

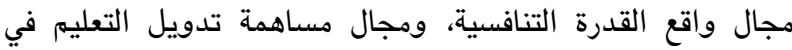

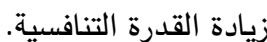

وأظهرت نتائج الدراسة عدم وجود فروق ذات دلالة احصائية

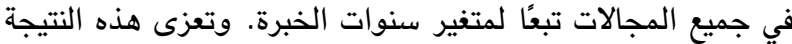

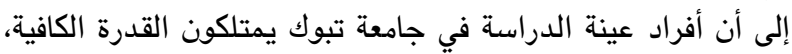

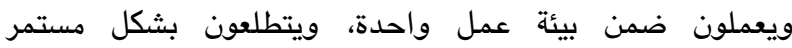
للمساهمة في الأنثطة والفعاليات التي تقدهها الجامعة، لإضفاء

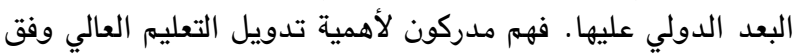

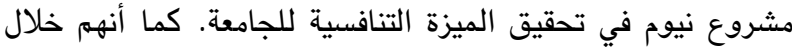

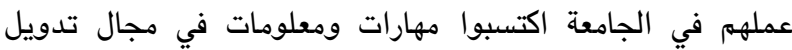

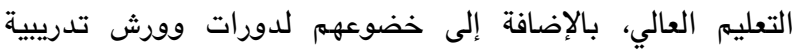
للنهوض بقدراتهم على التواصل مع الهيئات والجامعات العالمية.

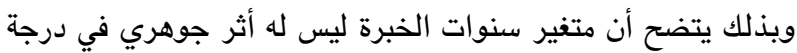
توجه جامعة تبوك نحو تحقيق الميزة التنافسية وفق مبادئ تدويل

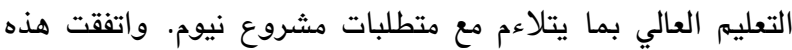

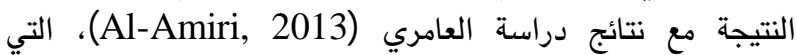
أظهرت عدم وجود فروق ذات دلالة إحصائية بين استجابات أفراد

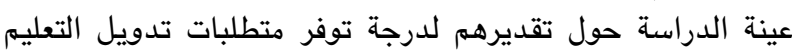
العالي في الجامعات السعودية الحكومية تبعًا لمتفير الخبرة.
المستوى العالمي، وتعزيز مسيرتها ودعمها لأجل مسايرة التطورات

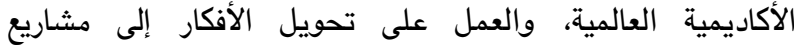
استثمارية مستقبلية، والتوسع في مساهمتها في المشاركة مع العالى العادية

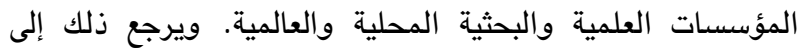

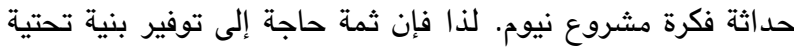

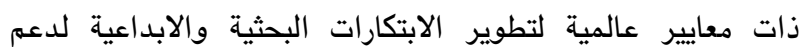

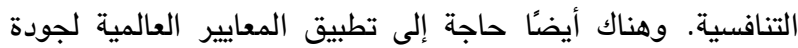

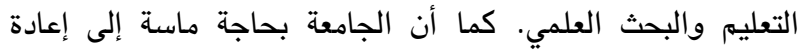

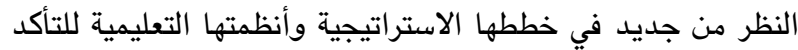
من رفع مكانتها العلمية وترسيخها ضمن متطلبات عالمية الجامعات.

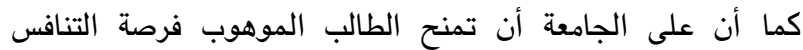

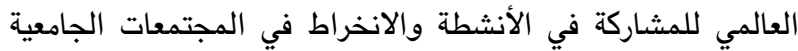
العالمية، وأن تحرص على إتاحة الفرص لأعضاء هيئة التدريس الأني

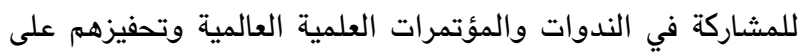
إحداث التغيير المطلوب في الجامعة لبلوغ العالمية، وفتح قنوات التيات

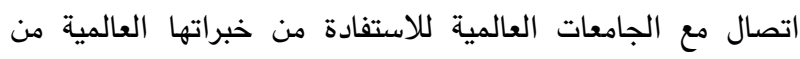

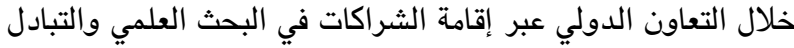

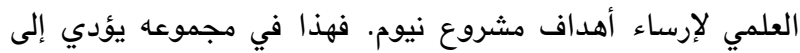

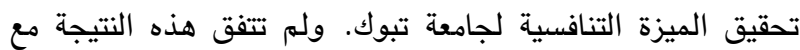
تنائج دراسة العامري (Al-Amiri, 2013) التي بينت أن درجة توفر متطلبات تدويل التعليم العالي في الجامعات السعودية التيات درية

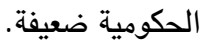

وأظهرت نتائج الدراسة المتعلقة بالسؤال الرابع عدم وجود

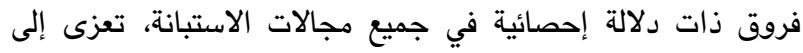
متغير المهام الوظيفية. ويمكن إرجاع هذه النتيجة إلى إلى وعي أفراد التاديا

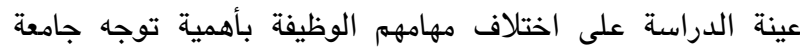
تبوك نحو تحقيق الميزة التنافسية وفق مبادئ تدويل التعليم العالي

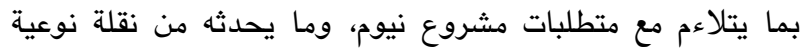

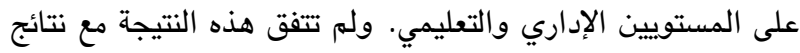

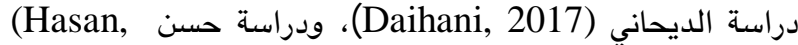
(2014، ودراسة عبيد الله (Obeidallah, 2017) ، ودراسة (Diاسة (Dراسة

نجوجي (Ngugi, 2014).

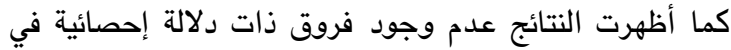

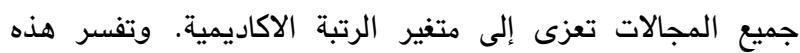
النتيجة بأن أفراد عينة الدراسة -على اختلاف رتبهم الأكاديميةيدركون أهمية توجه جامعة تبوك نحو تحقيق الميزة التنافسية وفق التقال

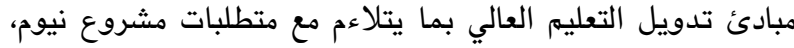

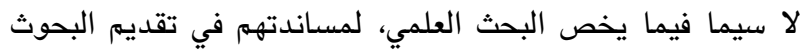

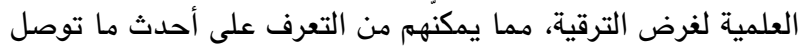

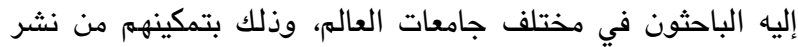

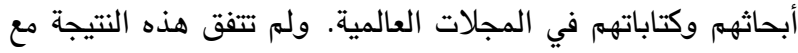

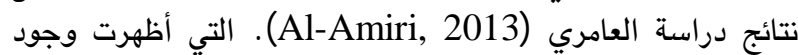
فروق ذات دلالة إحصائية بين تقديرات أفراد العينة لدرجة توفر التئ 


\section{References}

Al-Amiri, A. (3013). Higher education internationalization requirements as an approach for Saudi Universities global leadership: A proposed model. Unpublished $\mathrm{PhD}$ Thesis, Umm Al-Qura University, Makkah Al-Mukarramah, Saudi Arabia.

Aliabad, A. (2017). A proposed model to enhance competitiveness capabilities of King Saud University in light of international ranking standards of universities. The International Journal of Specialized Education, 6(3), 306327.

Al Saleh, O. (2012). The Competitiveness of higher education institutions: A suggested framework. Al-Baheth Magazine, (10), 297331.

Canadian Bureau for International Education (CBIE). (2014). Internationalization statement of principles for Canadian educational Institutions. Published Report, available at: https://cbie.ca/wp-content/uploads/2016/06/ Internationalization-Principles-for-CanadianInstitutions-EN.pdf

Chen, D. (2011). Internationalization of higher education in China and its development direction. Higher Education Studies, 1(1), 79.

Daihani, S. (2017). Developing the role of professional development for faculty members in achieving the competitive advantage of the University of Kuwait: A Perspective study. Educational and Psycho-logical Studies (Journal of the Faculty of Education in Zagazig University), (95), (2), 317-382.

Farag, S. (2019). The story of NEOM City: Opportunities and challenges. New Cities and Community Extensions in Egypt and the Middle East, 35-49.

Gao, X. (2015). On Internationalization of Higher education. International Conference on Arts, Design and Contemporary Education (ICADCE2015), ISBN 978-94-62520-78-3.

Gunsyma, S. (2014). Rationales for the internationalization of higher education: The case of Russia. Master Thesis. University of Tampere, Finland.

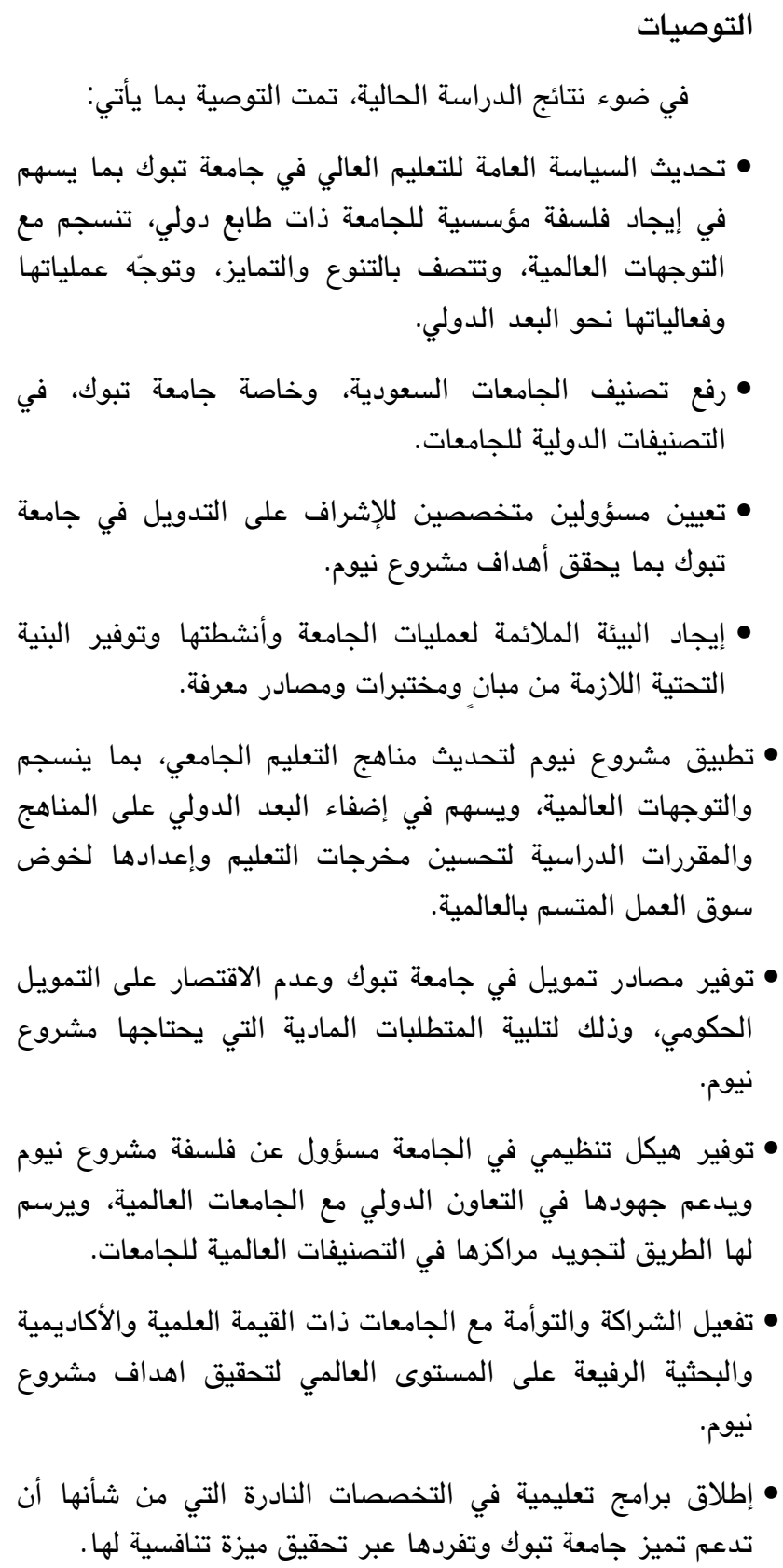


Hasan, M. (2014). Internationalization of education: An approach to increase the competitiveness of Egyptian Universities ،The Educational Journal, 29(113), 121-141.

Hawawini, G. (2016). The internationalization of higher education and business schools: Springer briefs in business. Available at: U.S.A. ISBN 978-981-10-1757-5. file://C:/ Users/only\%202/Downloads/9789811017551c2\%20(1).pdf

Hwang, J. (2017) The role of internationalization of higher education to achieve SDG4. Second Stakeholders Meeting on Indicators for Internationalization of Higher Education in Asia and the Pacific, Nov.9, 1-17.

Jibeen, T. \& Khan, M. (2015). Internationaliz-ation of higher education: Potential benefits and costs. International Journal of Evaluation and Research in Education, 4(4), 196-199.

Kamau, S. (2013) Competitive strategies adopted by private Universities in Kenya. Master Thesis, University of Nairobi.

Mainardes, E \& Ferreira, J. (2011). Creating a competitive advantage in higher education institutions: Proposal and test of a conceptual Model. Int. J. Management in Education, 5(2/3), 164.

Minawi, M. (2019) Saudi Arabia's Mega-city: The NEOM Project. Overview of public perceptions towards "the World's Most Ambitious Project". Available at: https://www.ipsos.com/sites/default/files/ct/ne ws/documents/2019-01/saudi_arabias_megacity_the_neom_project.pdf.
Ministry of Foreign Affairs in Denmark. (2018). Explore NEOM; the Futuristic City. Available at: file://C:/Users/ only\%202/Downloads/ NEOM\%20invitation.pdf.

Ngugi, R. (2014). Creating sustainable competitive advantage in institutions of higher learning: A case of United States International University. Master Thesis. International University.

Obeidallah, K. (2017). The effectiveness of applying the Baldrige Quality Standards in higher education to achieve competitive advantage: A case study on Jordanian Private Universities. International Journal of Business and Management, 12(11), 218.

Saudi_Vision2030_AR. https://www.vision 2030. gov.sa/ar/download/file/fid/353.

Saudi_Vision2030_AR.file://C:/Users/only/Downl oads/Saudi_Vision2030_AR.pdf

United Nations Educational Scientific and Cultural Organization (UNESCO). (2004). Higher education in a globalized society. Paris: UNESCO.

Yeravdekar, V. \& Tiwari, G. (2014) Internationalization of higher education and its impact on enhancing corporate competitiveness and comparative skill formation. Procedia - Social and Behavioral Sciences, 157, 203-209. 